\title{
THE GAP BETWEEN LATINO AND WHITE STUDENT ACHIEVEMENT IN ONLINE CLASSES
}

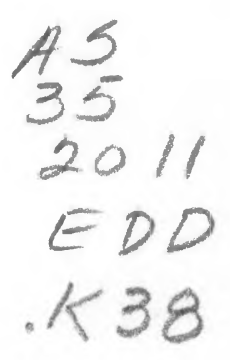

A dissertation submitted to the faculty of San Francisco State University in partial fulfillment of the requirements for the degree

\section{Doctor of Education}

in

Educational Leadership

by

Raymond E. Kaupp

San Francisco, California

May, 2011 
Copyright by

Raymond E. Kaupp

2011 


\section{CERTIFICATION OF APPROVAL}

I certify that I have read The Gap Between Latino and White Student Achievement in Online Classes by Raymond E. Kaupp and that in my opinion this work meets the criteria for approving a dissertation submitted in partial fulfillment of the requirements for the degree: Doctor of Education in Educational Leadership at San Francisco State University.
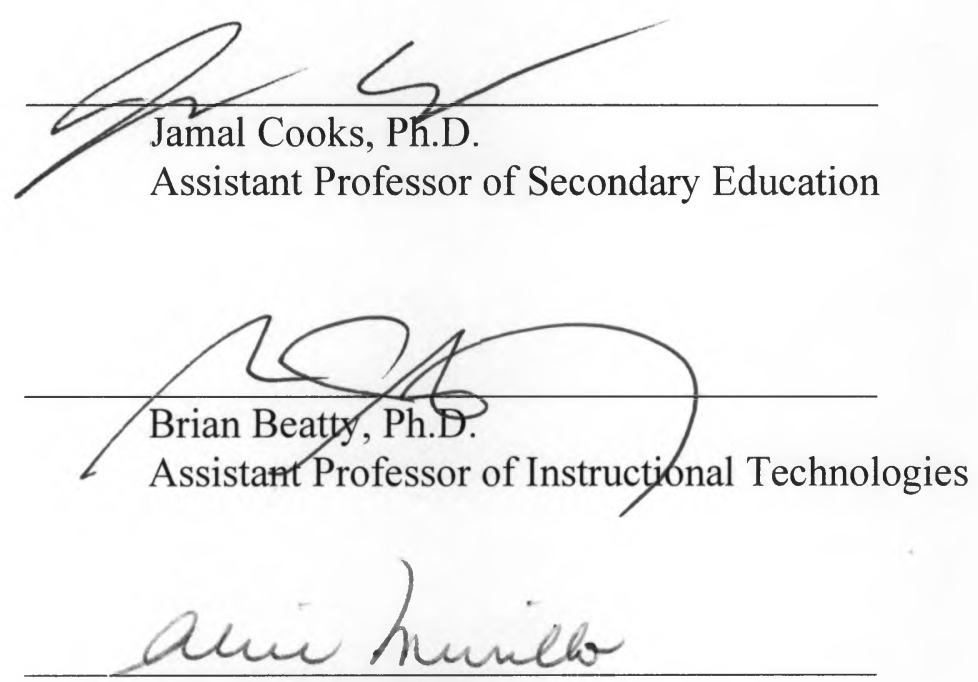

Alice Murillo, Ph.D.

Vice Chancellor, Academic Affairs

City College of San Francisco 


\title{
THE GAP BETWEEN LATINO AND WHITE STUDENT ACHIEVEMENT IN ONLINE CLASSES
}

\author{
Raymond E. Kaupp \\ San Francisco State University
}

2011

Despite a substantial body of research on the effectiveness of distance education at the post-secondary level, little is known about the impact of online course delivery on the achievement gap. In California, the gap between white and Latino post-secondary student outcomes is significant and persistent, with Latino students overrepresented in community colleges and underrepresented in transfers to four-year institutions. There is a broad consensus in the literature that online courses produce outcomes at least as good as face-to-face courses. However, in California community colleges, students enrolled in online classes don't do as well, in the aggregate, as their peers in face-to-face classes, experiencing lower completion rates and lower success rates. This explanatory, mixed methods study disaggregates statewide outcome data to assess the impact of online instruction on the achievement gap between white and Latino community college students, and examines factors contributing to this inequity. Online instruction was found to significantly exacerbate the achievement gap, with Latino students experiencing a nine percentage point lower success rate, grades that average two-tenths of a grade point lower, and withdrawal rates over twice as high, as Latino students in face-to-face sections of the same classes. Interviews with Latino students enrolled in online courses provided insight into the importance of relationships to Latino student success. The absence a strong student-instructor relationship was identified as the key difference between their face-to-face and online educational experience.

I certify that the Abstract is a correct representation of the contents of this dissertation.
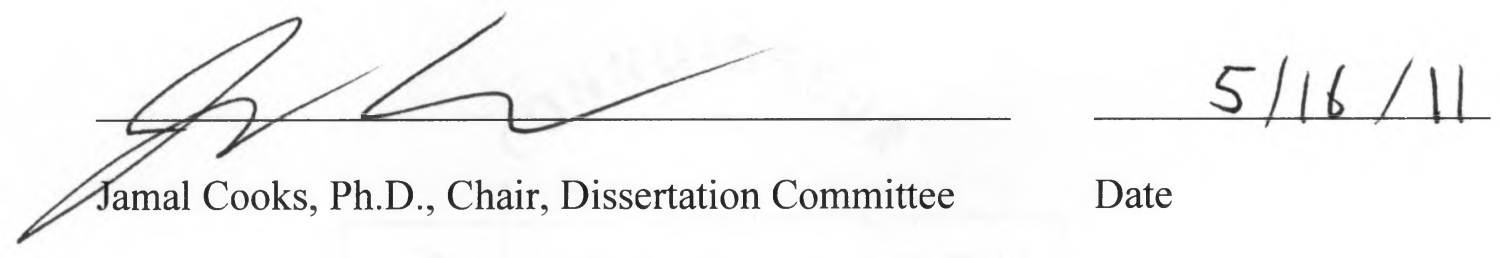

Date 


\section{ACKNOWLEDGEMENTS}

This dissertation has benefitted from the thoughtful critique, guidance and support of my committee chair, Dr. Jamal Cooks, and I thank him for his mentorship over the last three years. I also thank my committee members, Dr. Alice Murillo and Dr. Brian Beatty, for sharing their insights and suggestions. Dr. Robert Gabriner, director of the Ed.D. Program at San Francisco State University, challenged me early on to look at the equity issues surrounding technology adoption, helping focus my efforts on an area that clearly needed study. Finally, none of this would have been possible without the steadfast encouragement, love, and support of my wife and partner of 35 years, Jenny. She carried me through the rough spots, as she has always done, never doubting the outcome. 


\section{TABLE OF CONTENTS}

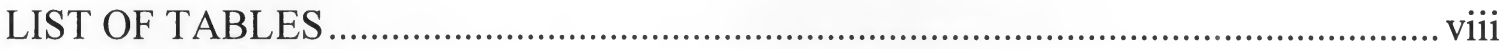

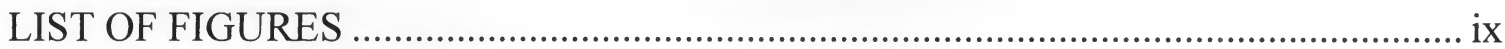

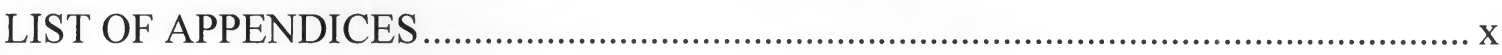

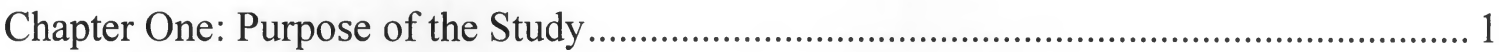

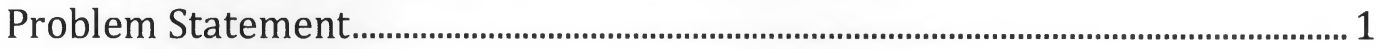

Research Question ................................................................................................................... 7

Conceptual Framework ............................................................................................................... 7

Definitions of Key Terms ...............................................................................................

Significance of the Study ......................................................................................................... 9

Chapter Two: Literature Review ................................................................................ 11

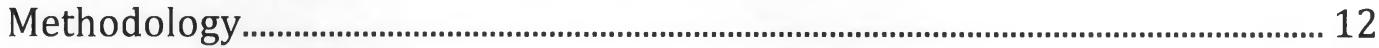

Education at a Distance ................................................................................................... 13

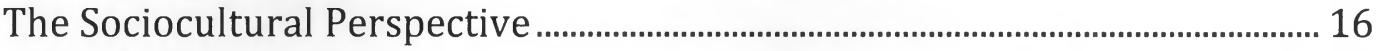

Systems Theory................................................................................................................... 20

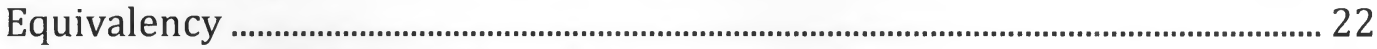

Satisfaction With Online Education ....………………………………………………... 26

Student Outcomes in Online Courses ........................................................................... 26

Private Sector Results ....................................................................................................... 32

The Achievement Gap ..................................................................................................... 33

Discussion ............................................................................................................................. 35

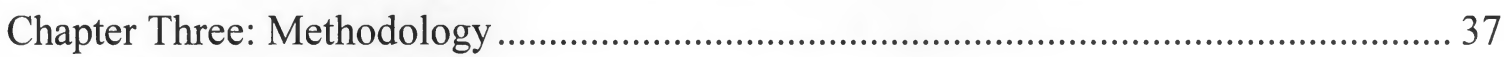

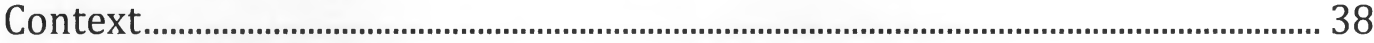

Role of the Researcher ........................................................................................................ 39

Ethics and Protection of Human Subjects .................................................................. 40

Quantitative Design and Analysis ................................................................................. 41

Qualitative Design and Analysis ....................................................................................... 45

Chapter Four: Report of Findings ............................................................................. 49

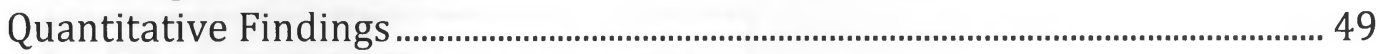

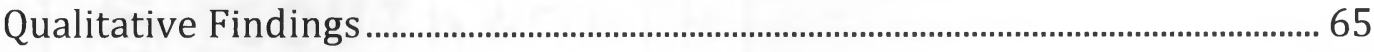

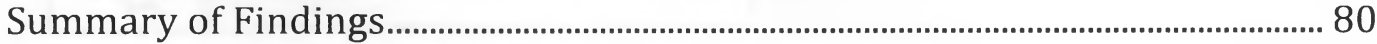




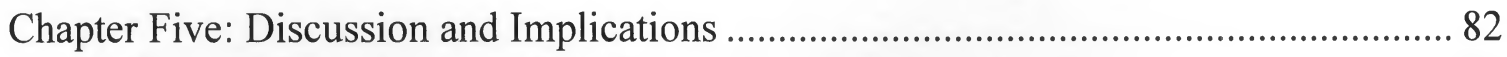

Overall Outcome in Online Classes ............................................................................... 83

Composition of Online Classes Masks Online Penalty.............................................. 83

Online Penalty Varies by Ethnicity, Gender, and Goal............................................. 85

Latino Student Deficits Rejected ..................................................................................... 87

Missing Instructor Relationship in Online Classes .................................................. 88

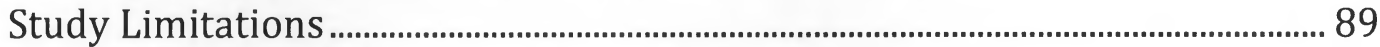

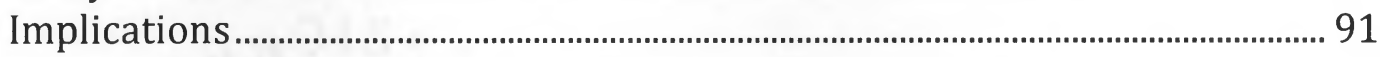

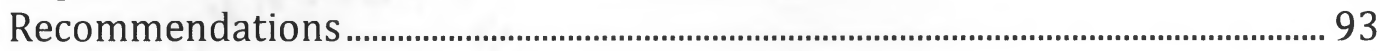

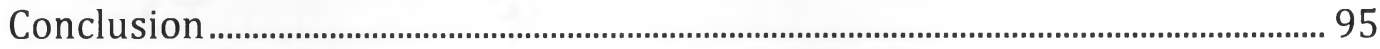

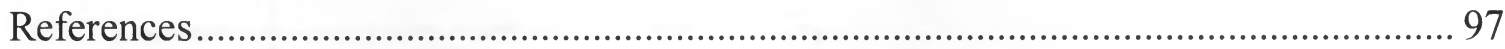

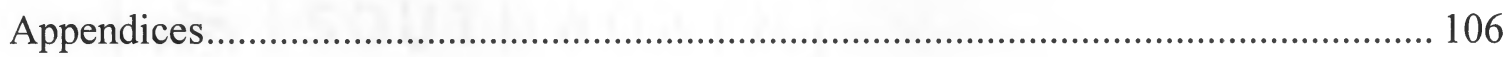




\section{LIST OF TABLES}

Table

Page

1. Costanza College Success Rate Percents by Ethnicity, Gender, and Class Format ....... 2

2. Costanza College Average Grade by Ethnicity, Gender, and Class Format.................. 3

3. Web 2.0 and Educational Practices......................................................................... 16

4. 2009-10 California Community College Enrollment by Ethnicity .............................. 39

5. Online vs. Face-to-face Average Grade by Student Goal .......................................... 51

6. Face-to-face vs. Online Average Grade, Goal to Update Job Skills........................... 52

7. Face-to-face vs. Online Average Grades, All Goals.............................................. 54

8. Face-to-face vs. Online Average Grades, Transfer and Vocational Goals .................. 55

9. Face-to-face vs. Online Average Grades, Underprepared Students ........................... 56

10. Face-to-face vs. Online Success Rate (\%), All Goals........................................... 57

11. Face-to-face vs. Online Success Rates (\%), Transfer and Vocational Goals ............ 59

12. Face-to-face vs. Online Success Rates (\%), Underprepared Students ....................... 60

13. Face-to-face vs. Online Average Grade, Transfer Goals in Transfer Courses ........... 62

14. Face-to-face vs. Online Average Grade, Vocational Goals in Occupational Courses .......................................................... 63

15. Face-to-face vs. Online Average Grade, Underprepared Students in Basic Skills Courses................................................. 64 


\section{LIST OF FIGURES}

Figure

Page

1: Percentage of online grades earned by ethnicity ......................................................... 4

2: Online penalty vs. face-to-face, in standard deviations, by student attribute and goal ........................................................................... 87 


\section{LIST OF APPENDICES}

Appendix $\quad$ Page

1. Appendix A: Qualitative Interview Protocol .................................. 106

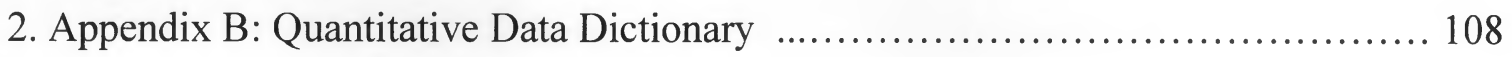




\section{Chapter One: Purpose of the Study}

Over the past several years, a consensus has formed that online instruction is neither better nor worse than traditional, face-to-face instruction. The two meta-analyses most often cited, summarizing 232 studies between 1985 and 2002 (Bernard et al., 2004), and 51 studies between 1998 and 2004 (Zhao, Lei, Yan, Lai, \& Tan, 2005), both concluded that the effect sizes were essentially zero, though with an extremely wide range of variability. In fact, Zhao et al. concluded that "distance education as a form of education is as good (or as bad) as face-to-face education" (p. 1861). More recently, the U.S. Department of Education released a rigorous review of 46 studies about outcomes for students in online learning, compared to face-to-face students (Means, Toyama, Murphy, Bakia, \& Jones, 2009). Means et al. concluded that there was a small positive effect, $+.24(\mathrm{p}<.001)$, for online instruction overall, when compared with face-to-face class formats.

\section{Problem Statement}

In contrast to this consensus in the literature, an analysis of student outcomes over three recent semesters revealed that Costanza College ${ }^{1}$ students did not do as well in online classes as in the face-to-face versions of the same courses. While these differences were quite small for White students, Latino students in online classes had significantly lower success rates and lower grade point averages than did Latino students in face-to-

\footnotetext{
${ }^{1}$ Costanza is the disguised name for a suburban California community college with $25 \%$ Latino and $61 \%$ White student enrollment.
} 
face versions of the same courses. In addition, Latino students' distribution of grades in online classes was skewed lower than both their White classmates in online classes, and their Latino classmates in face-to-face versions of the same courses.

Table 1 summarizes success rates, defined as a grade of $\mathrm{C}$ or better, in face-toface and online formats for Latino and White Costanza College students of both genders. In classes taught in a face-to-face format, the success rate for White students was just Table 1

Costanza College Success Rate Percents by Ethnicity, Gender, and Class Format

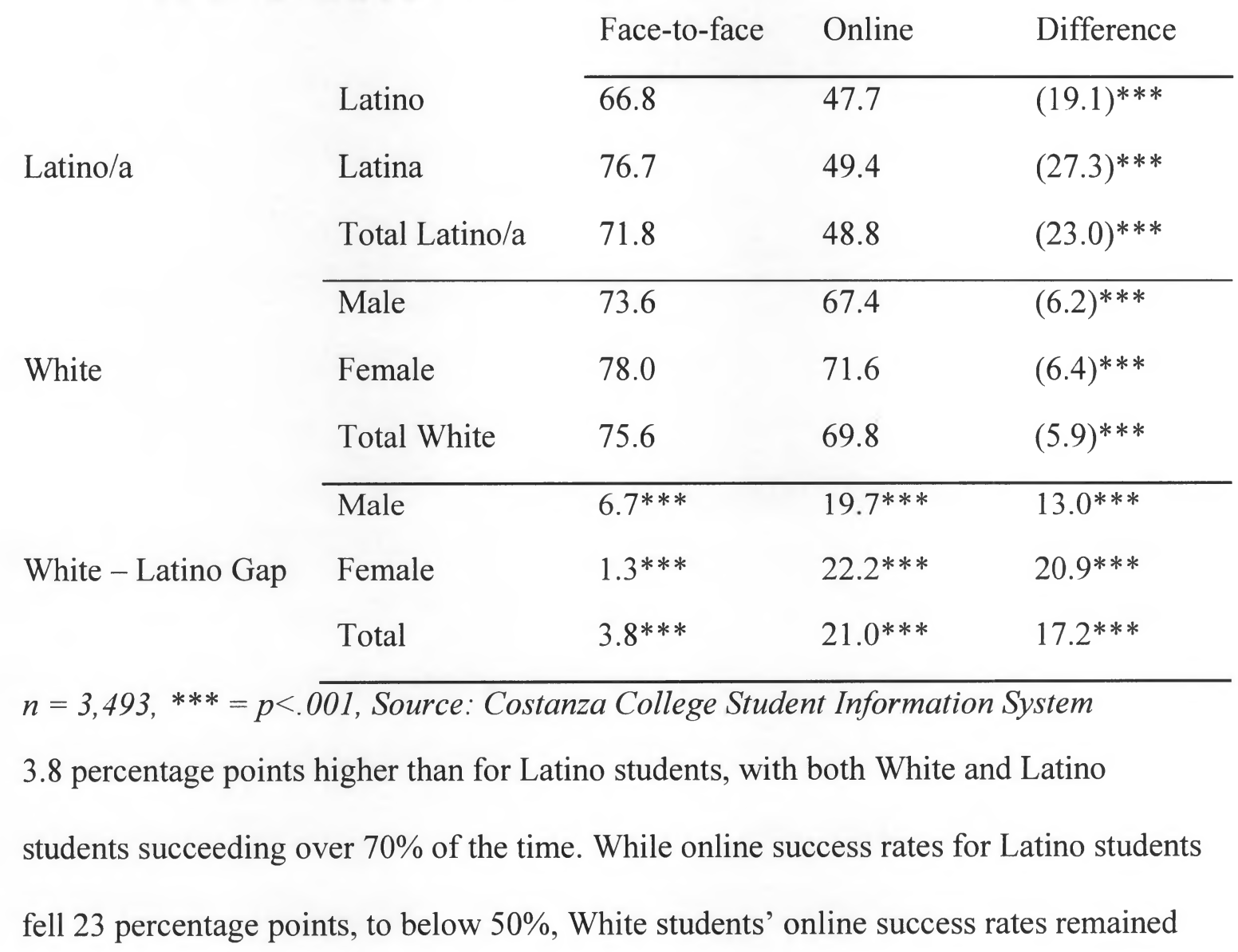


near $70 \%$. Accordingly, the gap between White and Latino students widened dramatically, to 21 percentage points, when both were enrolled in online courses.

Table 2 summarizes the average grades earned in face-to-face and online formats for Latino and White students of both genders. There was no statistically significant difference between the average of grades earned by White students in face-to-face Table 2

Costanza College Average Grade by Ethnicity, Gender, and Class Format

\begin{tabular}{|c|c|c|c|c|}
\hline & & Face-to-face & Online & Effect Size \\
\hline \multirow{3}{*}{ Latino/a } & Latino & 2.00 & 1.52 & $(0.32)^{*}$ \\
\hline & Latina & 2.35 & 1.54 & $(0.54)^{* * *}$ \\
\hline & Total Latino/a & 2.18 & 1.54 & $(0.43)^{* * *}$ \\
\hline \multirow{3}{*}{ White } & Male & 2.32 & 2.19 & $(0.09)$ \\
\hline & Female & 2.61 & 2.47 & $(0.09)$ \\
\hline & Total White & 2.45 & 2.35 & $(0.07)$ \\
\hline \multirow{3}{*}{ White - Latino Gap } & Male & $(0.21)^{* * *}$ & $(0.45)^{* *}$ & \\
\hline & Female & $(0.17)^{* * *}$ & $(0.62)^{* * *}$ & \\
\hline & Total & $(0.18)^{* * *}$ & $(0.54)^{* * *}$ & \\
\hline
\end{tabular}
Information System

classes and White students in online sections of the same courses. Also, the gender differences for White students, at 0.19 standard deviations for both face-to-face and online formats, fall below the Cohen (1992) threshold for meaningful effect sizes. 
Though the slight differences in face-to-face format average grades between White and Latino students of both genders were statistically significant, other than a small, 0.21 standard deviation difference between White and Latino males, there was no meaningful achievement gap between Latino and White students enrolled in the face-toface format courses. However, when enrolled in online courses, the gap between White and Latino males more than doubled, to 0.45 standard deviations. Latinas experienced an even larger negative impact in the online format, with a gap of 0.62 standard deviations between the average grades earned by White females and Latinas, in online courses.

Figure 1 provides a graphic representation of the difference in grade distribution between Latino and White students, of both genders, enrolled in online classes. A's and B's comprise over $58 \%$ of the grades earned by White students, but only $36 \%$ of the

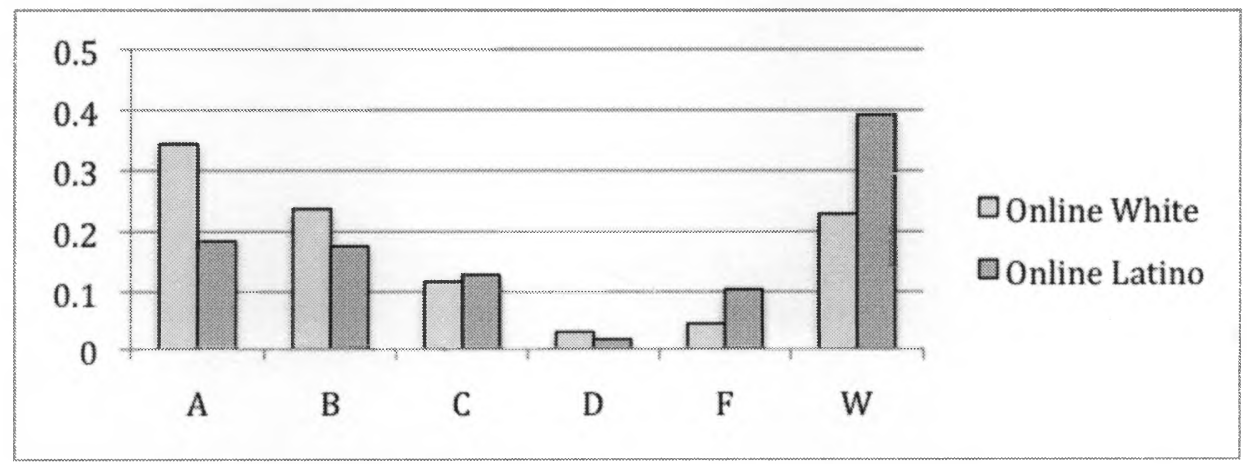

$X 2(5,535)=25.77, p<.001$, Source: Costanza College Student Information System Figure 1: Percentage of online grades earned by ethnicity grades earned by Latino students. At the opposite end of the range, D's and F's account for just $7.3 \%$ of the White students' online grades, and $12 \%$ of the Latino students' online grades. The largest disparity is for the withdrawal rate, with Latino students nearly twice 
as likely, at $39.2 \%$, to withdraw, as White students, at $22.9 \%$. In fact, this withdrawal rate for Latino students from online classes, compared to their White classmates, accounted for almost the entire gap in success rates discussed above.

At Costanza College, instructors and administrators cited student deficiencies in motivation, technology, and language as the causes of poor outcomes for Latino students in online sections. After claiming that some Latino students chose online sections because they thought the classes would be easier, one instructor added, "Motivation and willingness to 'show up' online make a huge difference." (personal communication, April, 2009). Another instructor, asked about the success rate gap between White and Latino students, responded, "I think it probably has to do with familiarity of the technology." (personal communication, April, 2009) An administrator stated that "more White kids ... will have high speed Internet connections at home, and a lot of Latino kids may be getting on Facebook in the library, or wherever, they may not have it at home." (personal communication, April, 2009) An administrator stated, “you've got folks that are linguistically in between two languages, and they don't know either one really well ... so there may be technology literacy issues, but plain old literacy issues too." (personal communication, April, 2009) An instructor said that "online students need to be able to read and comprehend written text better than face-to-face students." (personal communication, April, 2009) These typical responses have in common the effect of blaming students, rather than institutions, for poor outcomes. 
While each of these rationalizations could be argued on the facts, the larger issue is that attribution of poorer outcomes to deficits in Latino students tends to excuse faculty and administrators from critically examining the equity implications of online curriculum implementations. As community colleges are increasingly held accountable for student outcomes, online practitioners will need to shift the critique from the participants to the practice itself.

There has been little study of how subordinated student populations are faring in the online environment. The digital divide between high technology access and usage rates among White and Asian students on one side, and much lower rates among African American and Latino students on the other, has been well documented (Azzam, 2006), though this gap has closed dramatically in recent years (Jones, Johnson-Yale, Millermaier, \& Perez, 2009). Jones et al. found little statistical variation in the percentage of White and Hispanic U.S. college students with more than ten years of Internet experience, though White students were slightly more likely to have begun using the Internet at home, with Hispanic students more likely to have begun using the Internet at school (p. 255). Although there have been a few qualitative assessments of the experiences of African American students enrolled in an online graduate school program (Rovai \& Ponton, 2005; Rovai \& Wighting, 2005; Rovai, Gallien Jr., \& Wighting, 2005), no peer-reviewed studies of the impact of online course formats on Latino student achievement have been found. This void in the literature, combined with the preliminary 
findings from Costanza College and the overall poorer student outcomes in online classes at California community colleges, led directly to the research question for this study. Research Question

The research question for this study is: How does enrollment in online classes impact academic success for California Latino community college students?

\section{Conceptual Framework}

The conceptual framework for this study is anchored by (a) explicit rejection of a deficit model, in which subordinated students and their families are blamed for poorer outcomes; (b) institutional use of equivalency to adopt technology in education; and (c) the potential for the Internet to level playing fields. Above all, the approach emerges from a humanizing pedagogy, which grounds education in the mutually respectful relationship between teachers and learners (Bartolomé, 2009), a concept common across much of the literature about effective instruction for Latino students (Freire, 1970; Valenzuela, 1999; Solorzano \& Delgado-Bernal, 2001; Duncan-Andrade \& Morrell, 2008; Solorzano, Villalpando, \& Oseguera, 2005).

Definitions of Key Terms

Terms used in studies about online classes and student attributes can be grouped around (a) ethnicity and gender; (b) technology; and (c) measures of student outcome.

Ethnicity and gender: Where research is cited, the nomenclature used in the cited paper is employed. For this study, White refers to non-Asian, non-African American, non-Hispanic persons, with male and female used to define gender. Hispanic refers to 
persons with origins in Spanish-speaking parts of the world. A subset of the Hispanic population, Latino refers to ethnicity originating in Mexico, Central America, or South America. In this study, the gender inclusive form Latino is used when gender is not relevant, for example, when referring to the Latino-White achievement gap. When gender matters, the combined term Latino/a is used to describe both genders, while the gendered forms for male (Latino) or female (Latina) persons are used in specific comparisons, for example, Latinos compared to White males. When ambiguity is still possible, the grammatically redundant gender designation is included.

Technology: Synchronous instruction is defined by interactions that occur without delays, for example, in a typical classroom, on in a telephone conversation. Asynchronous instruction involves some time delay, for example, using email, or viewing a recorded lecture. Distance education refers to forms of education where the instructor and the students are separated by geography and time, and includes correspondence schools; television broadcast, called telecourses; and synchronous and asynchronous networkbased instruction. Face-to-face instruction refers to traditional instruction in a classroom. Online instruction is distance education delivered using the Internet, and is defined within the California community college systems as asynchronous Internet-based instruction.

Student outcomes: A course is an instructional unit, defined by particular content relevant to a subject area and designated with a course identifier that typically contains a subject abbreviation combined with a course number. For example, the course "Marketing Principles" would be identified as BUS82, where "BUS" places the course 
within the business curriculum at the college. Courses are also classified as transfer, if they satisfy undergraduate requirements of the CSU or UC systems; vocational, for courses that are primarily career or technical in nature; and basic skills, for courses offered to bring underprepared students up to college levels. A more comprehensive classification of courses is provided in Appendix 2.

Courses are offered during a particular semester in sections, also referred to as classes, which meet at specific times and places, and which are designated with a section or class format, such as online, face-to-face, or telecourse. A student achieves completion of a class by staying enrolled through the end of the semester. Success is defined as earning a grade of "C" or better in the class, or if the class is taken pass/fail, then by earning a pass. UC Success is defined as earning a grade of "B" or better in the class, since, while there are anecdotal exceptions, most University of California programs require a 3.0 grade point average for admission. The online penalty, discussed more fully in Chapter 4, refers to the difference in student outcome between online and face-to-face sections of the same class, expressed in percentage points when discussion success rates, and in standard deviations when discussing grade points.

\section{Significance of the Study}

This study will provide insight into the impact that online instruction is having on the achievement gap between White and Latino community college students in California, and will begin to explore potential cultural and attitudinal constructs driving the gap. It is hoped that this research will provide guidance to online practitioners, policy 
makers, and educational leaders, as they work toward equity while implementing online courses and programs in post-secondary educational settings. 
Chapter Two: Literature Review

There is a significant gap in post-secondary achievement levels between Latino students and White students. Latino students have lower participation and completion rates and a higher proportion of associates degrees (KewalRamani, Gilbertson, Fox, \& Provasnik, 2007). In San Francisco Bay Area high schools, just 6.5\% of Latino graduates meet the University of California (UC) eligibility requirements, compared to $16 \%$ of Whites and 31\% of Asians (Chavez, Medina, \& Arrdondo, 2007). These factors drive Latino students disproportionately to the community college system.

In some respects, Latino community college students achieve at a level comparable to their White classmates. One recent national study found that the persistence rate, the rate at which students complete a course regardless of the grade earned, was essentially the same for White and Latino community college students (Horn, 2009). An analysis of results for Costanza College, a typical California community college, revealed no difference between Latino and White students in the number of Associates' degrees awarded (Hayward, Cassada, Cordoba-Velasquez, \& Fillman, 2008). For the 2007/2008 academic year, both White students and Latino students earned twoyear Associates' degrees proportionate to their enrollment numbers.

When transfer rates to four-year institutions are considered, however, the achievement gap between Costanza's Latino and White students is quite dramatic. Costanza College reports aggregated transfer rates to UC and California State University (CSU) systems for underrepresented ethnicities, which includes African American, 
Filipino, Latino, and Native American students (Hayward, Cassada, Cordoba-Velasquez, \& Fillman, 2008). When these data are disaggregated, in 2008 Latino students accounted for just $13.6 \%$ of the UC transfers, and $20.2 \%$ of the CSU transfers, but accounted for over $25 \%$ of Costanza's enrollment. Statewide studies confirm that Latino students in California community colleges have substantially lower rates of transfer to four-year institutions than White students (Shulock \& Moore, 2007). This is especially troubling, since over half of all Latinos who pursue a post-secondary education begin their studies at a community college (Chavez et al., 2007).

Adoption of the Internet has led to explosive growth in college online course offerings. Nationally, total post-secondary online enrollment as a percentage of total enrollment grew from $9.7 \%$ in 2002 to $19.8 \%$ in 2006 (Allen \& Seaman, 2007). The attributes of the Internet and Web 2.0 technologies, collaboration and community, multiple pathways and access points to content, and pathways based on individual user attributes and actions (Millard \& Ross, 2006) seem tailored to providing leverage to help diverse student populations succeed academically. The impact of online instruction on student outcomes and the achievement gap is the subject of this literature review. Methodology

This literature review begins with a brief history of distance education, followed by a summary of the sociocultural perspective and the concept of discourses as a framework for understanding challenges faced by students from varied cultural backgrounds. Next, systems theory is presented as a framework for understanding the 
emergence of equivalence as the most prevalent criteria for institutional adoption of new technologies. Finally, an analysis of peer-reviewed studies is presented, from early efforts focused on student satisfaction, to the most recent efforts comparing student outcomes between online and classroom formats. A sampling of results reported by private, charter, and for-profit schools, and gleaned from non-academic publications, is also included. These anecdotes, while not typically included in an academic literature review, provide a sense of popular perceptions of the potential effectiveness of online instruction.

Studies for review were selected from the results of online database searches, with branching from early findings' reference lists. An initial search through Google Scholar, using the keywords "online classroom outcome", generated over 500,000 articles. Limiting the search to the exact phrase "online vs. classroom" reduced the list to around 130,000 articles, while adding a "community college" qualifier and a published date after 2003 produced just 14 articles. Branching from these 14 articles identified the three widely cited meta-analyses that form the foundation for this review. Subsequent searches in the ERIC, ProQuest, and Elvisier databases yielded the 24 representative studies included here.

\section{Education at a Distance}

Distance education has historically been linked to the available facilitating technologies. The earliest phase of distance education, correspondence study, leveraged the printing press and publishing industry, inexpensive mass-produced pens, and a cheap, reliable postal service (Hamilton, 1990) to meet the growing need for an educated 
workforce. In the United States, distance education can be traced to a 1728 advertisement in the Boston Gazette, offering to send shorthand lessons to rural students (Bower \& Hardy, 2004). William Rainey Harper, considered the "father of the American junior college" (Bower \& Hardy, 2004, p. 7), strongly supported correspondence education while he served as president of the University of Chicago in the 1880s. Newspaper publisher Thomas Foster began one of the most well known distance education efforts, the Pennsylvania-based International Correspondence School (ICS) in the late nineteenth century. ICS, now evolved into the Penn Foster Career School, still provides print-based, postal-delivered courses alongside their range of online offerings, at http://www.pennfoster.edu.

Radio, television, and magnetic recording technologies drove the next phase, multimedia distance education. By the 1920s nearly 200 radio stations in the U.S. were broadcasting distance education programs, and in the 1950s, Western Reserve University became the first U.S. college to offer regularly scheduled courses on television (Bower \& Hardy, 2004). The founding of the British Open University in 1969 was a key milestone in acceptance of distance education as a legitimate educational modality, providing worldwide full degree programs that leveraged satellite and shortwave television and radio broadcasting (Keegan, 1990). Early uses of computing technology for distance education followed the broadcast model as well, using media storage technologies like floppy disks and CD-ROM, to distribute educational content to students located remotely from their instructors (Sumner, 2000). 
The last phase of distance education, now more frequently referred to as online education, began with the Internet and the World Wide Web. The Internet, which in 1984 had reached a critical mass milestone of 1,000 connected host computers, provided an internationally recognized set of standards for inter-computer communication. In 1991, the World Wide Web was released by the European Organization for Nuclear Research, known more commonly as CERN (the abbreviation of the French Conseil Européen pour la Recherche Nucléaire). The Web changed everything by organizing an easy-to-use set of protocols, layered on top of the somewhat esoteric and convoluted structures of the underlying networks, thus providing non-technical users with access to the Internet's powerful communication, information management, and multimedia features.

The most recent inflection point for online education came with the advent of Web 2.0. Tim O'Reilly, credited with launching this paradigm shift at his first annual Web 2.0 Conference in 2004, explains it best:

Web 2.0 doesn't have a hard boundary, but rather a gravitational core. You can visualize Web 2.0 as a set of principles and practices that tie together a veritable solar system of sites that demonstrate some or all of those principles at a varying distance from that core. $(2005, \boldsymbol{9})$

The principles O'Reilly articulated, which include (a) user control of their own data, (b) an architecture of participation, (c) remixable data sources and data transformations, and (d) harnessing collective intelligence (O'Reilly, 2005), spawned a 
set of technologies that are just now starting to appear in online courses. Table 3 presents examples of these technologies, mapped to common educational best practices.

Table 3

Web 2.0 and Educational Practices

\begin{tabular}{l|l}
\hline Educational Practice & Example Internet/Web 2.0 Technologies \\
\hline Collaborative learning & Forums, blogs, and chat, wikis and social networks \\
Individualized instruction & Personalization engines, dynamic content generation \\
Accommodation of different & $\begin{array}{l}\text { Animation, video/audio streaming, interactive } \\
\text { simulations }\end{array}$ \\
learning styles & Search, html-linked content \\
Discovery-based learning & Versioning, multi-language user interfaces, social \\
Culturally relevant instruction & networks \\
Constructivist learning & Blogs and wikis \\
Assessment and remediation & Response-based navigation, interactive testing systems \\
\hline
\end{tabular}

Social networking sites like Facebook and LinkedIn have integrated many features of Web 2.0 into systems that have grown to communities of millions of users. These same features could be deployed to support a sociocultural approach to online education.

The Sociocultural Perspective

The sociocultural perspective has its roots in Vygotsky's concept of the zone of proximal development (ZPD), where he believed that sociocultural development occurred (Matusov \& Hayes, 2000). Although often expressed in terms of interactions between adult and child, the ZPD is also thought to operate when learners collaborate with more 
capable peers (Vygotsky, 1978). Sociocultural theory postulates that "cognitive development is embedded in social contexts" (Matusov \& Hayes, 2000, p. 215), and thus learning is inseparable from these contexts. These social contexts produce what Bourdieu called habitus: "systems of durable, transposable dispositions" (1990, p. 278), that guide the learner through acquisition of new knowledge.

There is a close correspondence between habitus and the framework of discourses, articulated by Gee in his discussion of literacy as control of a secondary discourse (1989). Gee reminds us that students arrive in the classroom fully literate in their primary discourse, the language and social context in which they were raised. Academic literacy requires them to achieve control of a new, academic discourse, with the degree of congruence between the primary and academic discourses mediating the difficulty of achieving success. Simply put, students whose primary discourse is similar to the secondary, academic discourse will have an easier time in school that those with a dissimilar primary discourse. Good teachers are sensitive to their students' primary discourses, and help them make connections to the academic discourse under study.

Latino students face specific challenges navigating the dominant, academic discourse. The Mexican cultural construct of educación, based on mutual respect among teachers and learners stands in stark contrast to typical Latino student experiences (Valenzuela, 1999). Male Latinos are often "policed, contained, and treated as criminal threats in ... their schools and neighborhoods." (Cammarota, 2004, p. 54) Instead of marginalizing and subordinating Latino students, successful teachers create respectful 
relationships that foster critical thinking and improved outcomes, often framing their approaches in pedagogical theories, including critical theory (Duncan-Andrade \& Morrell, 2008) and LatCrit theory (Solorzano \& Delgado-Bernal, 2001), evolved from Paolo Freire's seminal Pedagogy of the Oppressed (1970).

Writing from his experiences educating illiterate members of Brazil's peasant class during the mid-twentieth century, Freire (1970) was highly critical of the traditional, industrial model of education. He referred to it as a "banking" concept, in which the teacher deposits knowledge into the student, in two stages:

During the first [stage], he cognizes a cognizable object while he prepares his lessons in his study or his laboratory; during the second, he expounds to his students about that object. The students are not called upon to know, but to memorize the contents narrated by the teacher. (p. 80)

Freire argues that this banking model only serves to perpetuate oppression of subordinated populations. He proposes instead a pedagogy of dialogue, where teacher and student interact in a mutually respectful relationship, with each bringing valuable knowledge to the interaction.

Freire's relational approach to education resonates with the Mexican sociocultural construct of educación. This term includes the academic aspects of North American schooling, but is conceptually much broader, encompassing social competence and respect for others as well. As Valenzuela (1999) describes it, "Educación thus represents 
both means and end, such that the end-state of being bien educada/o [well educated] is accomplished through a process characterized by respectful relations." (p. 23)

The educación construct is central to the Puente Project, a successful program designed to increase transfer rates of Latino community college students. Founded at Chabot College in Hayward, California, Puente (the Spanish word for "bridge") has spread to over 40 2-year colleges throughout California. Nearly half of the students who complete the program subsequently transfer to a 4-year college or university (Rendón, 2002). A central element of the Puente Project is assignment of a mentor, a volunteer college instructor or administrator, for each student participant. Activities, projects, and assignments throughout the academic year are designed to build the relationship between mentor and mentee, consistent with the goal of a bien educada/o student.

Central to this approach is an understanding that teaching and learning is fundamentally a social activity. As Delpit (1995) argues, "the actual practice of good teachers of all colors typically incorporates a range of pedagogical orientations." (p. 24) In a similar vein, Bartolomé (2009) encourages teachers to move past the focus on methods and techniques, and instead asks, "Is it not merely common sense to promote approaches and strategies that respect, recognize, utilize, and build on students' existing knowledge bases?" (p. 344) This humanizing pedagogy, common across much of the literature on effective teaching and learning for subordinated student populations, will be central to closing the Latino-White achievement gap. 
Technology has historically been used to leverage human effort. The technologies embodied in Web 2.0, especially those supporting its relationship-building focus, are particularly appropriate for development of online education that embodies a humanizing pedagogy.

Systems Theory

Ludwig von Bertalanffy (1968) is widely credited with synthesizing work across a range of disciplines, including biology, psychology, sociology, physics, and mathematics, into a generalized theory of systems. A system is "a set of elements standing in interrelations." (p. 55) The elements in a complex system are often systems of their own, with both internal processes through which their work is performed, and boundary processes, through which these subsystems interact with other subsystems. Open systems are those that interact with their external environment. Accordingly, application of system theory to educational organizations is always from an open systems perspective, since schools interact with students, families, governments, communities, suppliers, and many other external entities.

Open systems have several common attributes regardless of the discipline under study. Bertalanffy (1968) defined these as:

hierarchy, in which larger systems are comprised of groups of subsystems; synergy, where the sum is more than the parts; growth, especially as the concept relates to the limit, beyond which additional “tinkering" doesn't increase output; 
competition, in which elements within a system vie for what are often limited resources; and

finality, where the system has achieved fitness for its purpose, in a steady state of equilibrium, which then becomes difficult to disrupt.

This last point, when applied to educational institutions, is clearly evident in the way these institutions resist change, instead striving to maintain the status quo.

In educational settings, interactions among subsystems are usually characterized as loosely coupled (Weick, 1976). This concept posits a range, from tight to loose, of possible connections between systems. A loose coupling implies that, while two systems can be responsive to each other, each maintains a separate identity, and "their attachment may be circumscribed, infrequent, weak in its mutual affects, unimportant, and/or slow to respond." (p. 3) In contrast, tightly coupled systems will be highly responsive, and thus more easily adaptive to external disruptions to the status quo. Some argue that loose coupling is often employed by administrators to buffer the instructional core of the institution by insulating teachers from outside influences, while giving the appearance of managing instruction (Elmore, 2004).

Mars and Ginter (2007) employed Weick's framework of tight versus loose coupling to compare adoption of instructional technology across three colleges. Two urban community colleges were characterized as typical loosely coupled educational institutions, while the contrasting, disguised "High-Tech College" appears to be a fast growing for-profit organization with a tight coupling among organizational subsystems. 
They conclude that, loosely coupled institutions are not effective integrating instructional technology, while tightly coupled institutions will do a better job taking advantage of technology to improve operations at the instructional core.

In the loosely coupled systems environment of California's community colleges, equivalence becomes the key framework operating at the boundaries between subsystems. Individual colleges are able to grant the same degrees and certificates because they offer courses and programs that are equivalent, even though there is wide variation in the courses themselves. Four-year universities accept prerequisite courses taken at the community college because their articulation agreements define these courses as equivalent to those offered at the university, whether they actually are or not.

\section{Equivalency}

Public schools also use equivalence to adapt technical innovations to the educational mission, often hobbling these innovations with pre-existing pedagogy: Whiteboards are dustless chalkboards, video a new way to show films, and computers just typewriters that are easier to edit with. Similarly, public schools have largely adopted Internet technologies as analogues of classroom pedagogy, rather than as completely new tools that enable completely new outcomes (Christensen, 2008).

An early theoretical discussion of online education articulated equivalency theory, stating, "Distance education's appropriate application should provide equivalent learning experiences for all students - distant and local —in order for there to be expectations of equivalent outcomes." (Simonson, 1999, p. 7) Simonson presented equivalency theory as 
a standard that could be employed for adoption of online instructional technology. He correctly argued that, before implementing a change, a new technique must be at least as effective as the existing technique it proposes to displace, thus setting the bar at the status quo. However, equivalency theory is often operationalized as a requirement for equivalence across the elements and attributes of each course, rather than as an equivalence of outcomes.

In the California community college system, some form of equivalency between classroom and online courses is often an explicit goal. Community college accreditation documentation includes the requirement that the college "hold all courses and all operations related to distance education to the same standard as those for on-campus classes." (personal communication, April, 2009) An example of this appeared in a draft version of the Costanza College Distance Education Master Plan, which set the goal of online education as "creating the virtual equivalent of the face-to-face classroom." (personal communication, April, 2009)

Equivalency concepts are pervasive throughout institutional policies and documents. A 2008 Costanza College faculty grant program, designed to encourage development of online courses, created incentives for equivalency between classroom and online courses (personal communication, September, 2007). The scoring system for the program, used to determine which grant applications would be approved, awarded one to three points for adoption of e-packs or publisher-developed e-learning courses. In contrast, a program application for conversion of an existing face-to-face course was 
awarded four to six points, which doubled the likelihood of approval of the grant application. The grant program clearly rewarded conversion of existing courses, thus encouraging equivalency, regardless of which approach was more effective.

The Costanza College Federation of Teachers (CCFT), representing instructors in collective bargaining at Costanza, has also struggled with equivalency. For example, online instructors are currently evaluated by mailing the existing, classroom-oriented, student evaluation forms to the enrolled students. Peer evaluations of online instructors are often performed only on their traditional-format classes, since the concept of a "classroom visit" does not translate well to the online environment. As some instructors transition to a fully online teaching assignment, even these traditional evaluations become unavailable. Over the last two years, a CCFT task force has developed a set of equivalency-based recommendations for approval into the faculty contract, including (a) if possible, including an experienced DE instructor on the peer evaluation team, (b) revising the student evaluation form to ask questions related to timeliness of response to student assignments and questions, (c) administering student evaluations online, providing that responses are only processed by division staff, and that student anonymity is protected, and (d) developing a simple classroom observation form to evaluate methods of contact between student and instructor. (personal communication, May, 2010) It is interesting to note how the language classroom observation form carried forward to the online environment, where no room is involved in the instructional practice. 
Costanza's focus on equivalency between classroom and online courses is completely consistent with policies from the California community college chancellor's office. Equivalency is the clear goal from the system office, and achievement of equivalency is often heralded with pride. As the subject of one recent chancellor's office communication stated, "DE offerings have been mainstreamed." (personal communication, May, 2010) The purpose of this particular document was to notify colleges in the system that they could now "compute DE Full Time Equivalent Student (FTES) using the same attendance accounting procedures available to a classroom-based course." (personal communication, May.2010)

Empirical studies often attempt to "control" for equivalency. Couched in terminology that characterizes the online environment as a "virtual" classroom (Benson et al., 2005; Larreamedny-Joerns \& Leinhardt, 2006; Lapsley, Kulik, Moody, \& Arbaugh, 2008; Lim, Morris, \& Yoon, 2006), some practitioners attempt to justify inclusion of online courses in their curriculum by replicating, as much as possible, the face-to-face classroom environment.

Although equivalency may make it easier to get institutions to adopt online versions of existing classes, attempts to replicate the face-to-face environment negate many potential advantages of new technologies. One study of over 800 instructors' utilization of features within an Internet-based course management system revealed that less than $5 \%$ of them employed innovative features like virtual office hours, live chat, student-generated web pages, or social discussion forums (Woods, Baker, \& Hopper, 
2004, p. 293). Yet these are the very features most useful to facilitate culturally relevant learning, based on relationships, with subordinated students.

\section{Satisfaction With Online Education}

Early studies of online education focused on the satisfaction levels experienced by students. Typical of these studies, Uschi Felix (2001) provides modest guidance for developers of Web-based materials, since his research identified clear and logically organized content, clear objectives, meaningful feedback, and easy navigation as course elements important to students. Not surprising, students also became more comfortable with Web-based materials as they used them. Like others reporting satisfaction (e.g. Kennedy, Eizenberg, \& Kennedy, 2000; So \& Brush, 2008; Rovai \& Barnum, 2003; Lim et al., 2006), Felix avoids any measurement of student achievement. But what else matters? The presumption is that achievement is a derivative consequence of the comfort and enjoyment measures in this study: Happy students learn more. Felix cites no evidence for this connection, instead dismissing achievement as beyond the scope of his paper.

\section{Student Outcomes in Online Courses}

More recently, an increasing number of studies of online education have reported on student outcomes, in the form of test scores, evaluations, grades, or other measures, compared to outcomes for students in traditional face-to-face courses. While some, like Hannay and Newvine (2006) have reported large positive effect sizes for online courses, and others, like Mullen et al. (2006), have reported large negative effect sizes for online 
courses, the more dramatic results, in either direction, seem to be accompanied by significant flaws in study design.

One of the few early, rigorously designed studies, looking at outcomes for several hundred University of California introductory economics students (Navarro \& Shoemaker, 2000), used scores on a final exam to compare online student outcomes with those of students in a traditional, face-to-face class. The same exam, consisting of fifteen short essay questions requiring some application of macroeconomic principles, was given to each group, and was scored blindly by a single instructor. In this study, students enrolled in the online section scored significantly better $(p<.01)$ with a mean score of $11.3(\mathrm{SD}=2.6, \mathrm{n}=48)$, than did students in the face-to-face section, with a mean score of $9.8(\mathrm{SD}=2.5, \mathrm{n}=145)$. Although this study did not include an analysis of the effect size of this difference, the reported standard deviations enable the effect size to be calculated as .58 standard deviations. This corresponds to a medium effect size, according to Cohen's (1992) classification of effect sizes as small, 0.20, medium, 0.50 , or large, 0.80.

Over the past several years, a consensus has formed that online instruction is neither better nor worse than traditional, face-to-face instruction. The two meta-analyses most often cited, summarizing 232 studies between 1985 and 2002 (Bernard et al., 2004), and 51 studies between 1998 and 2004 (Zhao et al., 2005), both concluded that the effect sizes were essentially zero, though with an extremely wide range of variability. In fact, Zhao et al. concluded that "distance education as a form of education is as good (or as bad) as face-to-face education" (p. 1861). The first chapter of a widely cited compendium 
of best practices in higher education online course design points out, "One cannot say that, in general, distance education is of high or low quality any more than we can commend or condemn lectures or seminars." (Duffy, 2004)

More recently, the U.S. Department of Education (DOE) released a rigorous review of 46 studies about outcomes for students in online learning, compared to face-toface students (Means et al., 2009). To be included in the analysis, Means et al. required that studies (a) involve learning over the Internet, (b) compare outcomes between online and other formats, (c) describe a completed study with a learning outcome measured for both treatment and control groups, (d) use an experimental or quasi-experimental design, and (e) include enough data to allow calculation or estimation of an effect size. Effect sizes were calculated as the number of standard deviations separating the means of the treatment and control groups, with a "+" or "-" sign indicating a better or worse outcome, respectively, for the treatment group. To characterize the relative importance of the differences, the authors cited Cohen's (1992) small, medium, and large classification system, mentioned earlier.

Means et al. concluded that there was a small positive effect, $+.24(\mathrm{p}<.001)$, for online instruction overall, when compared with face-to-face class formats. When the findings were subcategorized, a slightly stronger effect,$+.35(\mid \mathrm{p}<.001)$, was identified for classes that blended online and face-to-face components, and undergraduates had proportionally better outcomes,$+.35(\mathrm{p}<.001)$, than graduate students $,+.17,(\mathrm{p}<.05)$. 
One of the most intriguing findings from this report related to the effect of attempts to duplicate face-to-face pedagogy in the online environment. Studies where conditions varied between formats, across multiple aspects of instruction, reported an online advantage twice as large, $+.42(\mathrm{p}<.001)$, as were seen in studies where equivalency was attempted between online and face-to-face formats, $+.20(\mathrm{p}<.001)$ (Means et al., 2009). Means et al. essentially suggest that equivalency criteria reduce, rather than improve, the effectiveness of online course implementations.

Reaction to this 2009 DOE report on online learning (Means et al., 2009) has been mixed (von Lehmen et al., 2010). The most rigorous critique of Means et al. emerged from the Columbia University Teachers College, Community College Research Center (Jaggars \& Bailey, 2010). Jaggars and Bailey argue that, while proponents of postsecondary online education are citing the DOE report as evidence that students do better in online courses than in face-to-face courses, "such an interpretation is not warranted when considering fully online courses in the typical postsecondary setting." (p. 2) Jaggars and Bailey then go on to disaggregate the studies included in the DOE meta-analysis, pointing out that less than half of the fully online courses included by Means et al. were semester-length college courses. They are also critical of the methodology of many of the remaining studies.

By disaggregating the studies in the DOE report, Jaggars and Bailey negate the central purpose of meta-analysis as a research technique. Meta-analysis is ideally suited as a technique to further our knowledge in areas where multiple studies have produced a 
range of apparently conflicting outcomes (Hunter, 2004). Meta-analysis is employed to generate knowledge from precisely the sorts of studies that Jaggars and Bailey argue against including. When Glass (1976) first argued in favor of meta-analysis, he bemoaned this sort of critique, stating:

A common method of integrating several studies with inconsistent findings is to carp on the design or analysis deficiencies of all but a few studies - those remaining frequently being one's own work or that of one's students or friends - and then advance the one or two 'acceptable' studies as the truth of the matter. (p. 4)

This prescient characterization of the Jaggars and Bailey critique is further supported by the subsequent release of a study, led by Jaggars, of student outcomes in online classes in the Virginia community college system.

The Virginia study (Jaggars \& Xu, 2010) tracked four years of enrollment patterns and success rates for a cohort of around 24,000 first-time community college students, who started college in 2004. A second cohort of students who started in 2008 was also analyzed to validate the study findings from the first cohort. One unspoken assumption of the study is that students had a choice regarding the format of the classes they took; that is, each desired course was offered in both online and face-to-face formats in the semester during which the student wanted or needed to take that course. 
Enrollment in online courses was skewed along multiple student attributes. Black and Hispanic students were less likely to take an online course than were White students. The study also reported that

online courses were significantly more popular among females, English-fluent students, those who applied for and were eligible for financial aid, who never enrolled in remedial education, who were above 25 years old at college entry, who had earned credits in previous semesters, who had enrolled in computer literacy or development courses, and who had attempted online courses before.(Jaggars \& Xu, 2010, pp. 6-7)

Although significance is defined in a footnote to mean statistical significance $(p<.05)$, there is no information provided about the magnitude of the differences, and accordingly, whether the reported differences in enrollment patterns are particularly meaningful.

The analyses of course completion, which Jaggars and $\mathrm{Xu}$ define as the student earning a D or better in the course (2010), and of subsequent semester student retention, were restricted to only those students who had attempted at least one online course. The course completion rate for online courses attempted by these "ever-online" students was $68 \%$, compared to a face-to-face course completion rate of $81 \%$, among the same cohort of students $(2010$, p. 34). Overall semester-to-semester student retention is essentially the same between students who took an online course and those who did not (2010, p. 34). An additional analysis that attempted to control for the previous findings that "students who chose online coursework were also students who had other characteristics typically 
associated with short- and long-term outcomes" (2010, p. 16), found a 3\% to 5\% higher retention rate for students who did not take an online class in their first or second semester (2010, p. 16). Although data about the ethnicity of students was available, no analysis was presented regarding differences in outcomes based on ethnicity.

The outcomes reported by Jaggars and Xu (2010) for the Virginia community college system do not compare favorably with other studies. For example, the California community college system reports a consistent, overall 5\% lower success rate for online classes, compared to face-to-face classes (Nather, 2007). Virginia's 13\% lower success rate for online classes (Jaggars \& Xu, 2010) seems much worse by comparison. These findings, released as they were just two months after Jaggars' negative critique of the DOE study (Jaggars \& Bailey, 2010), may at least partially explain that critique.

Nowhere do they ask the obvious question: What is it about the Virginia community college system's online classes that produces results so much worse than other studies would predict?

\section{Private Sector Results}

Startup companies in the private sector and charter schools, unencumbered by existing curriculum and glacial change processes, are producing positive outcomes with adoption of online technology. San Diego-based High Tech High Schools, founded by former Qualcomm executive Gary Jacobs and supported by funding from the Bill and Melinda Gates Foundation, has seen enrollment grow from 50 students to 2,500 in just 5 years, with $100 \%$ of their graduates accepted to a college or university (HighTechHigh, 
2008). Private tutoring company PLATO Learning has seen dramatic growth since converting their curriculum to a browser-based learning management system that provides highly personalized, assessment-based access to material for students who have previously failed basic skills courses (Trotter, 2008). Apex Learning, founded in 1999 with funding from Microsoft co-founder Paul Allen, has recently extended their online course offerings from the original suite of advanced placement classes, to include a full range of high school curriculum, with enrollment growing $50 \%$ per year to 300,000 students last year, according to CEO Cheryl Vedoe (Szep, 2008).

Unfortunately, information about specific outcomes produced in these for-profit institutions is often reported in their marketing materials, rather than in rigorous, peerreviewed journals. We should also be aware of a possible selection bias in the for-profit sector results, since their students are not likely to represent the broad cross section of race, class, and socioeconomic diversity we see in public schools.

The real truth of the matter is that, while online teaching and learning has some constraints and advantages when compared to face-to-face teaching and learning (Duffy, 2004), it is not inherently, in any particularly meaningful way, better or worse.

\section{The Achievement Gap}

Though the digital divide between high technology access and usage rates at home among White and Asian students on one side, and much lower rates among African American and Latino students on the other, has been well documented (Azzam, 2006), the access gap in school settings has essentially disappeared. In fact, a study in southern 
California high schools during the 2001-2002 academic year found that low-SES schools, each of which had at least $44 \%$ Hispanic students, had a slightly better ratio of computers and Internet connections per student than did high-SES schools, where less than $13 \%$ of the students were Hispanic (Warschauer, Knobel, \& Stone, 2004).

Warschauer et al. (2004) analyzed issues related to student usage of technology across three categories: performativity, workability, and complexity. Performativity refers to usage related to skills development, "ticking off checklists of skills without paying due attention to larger issues of knowledge construction and purposeful learning." (p. 574) Workability was a measure of the accessibility and usability of the installed technology for learning purposes, that is, the extent to which it worked. Complexity refers to the idea that, even when the technology worked, "many teachers still found it a complex undertaking to actually integrate computers in their teaching." (p.581) The study found that issues related to complexity were more prevalent at low-SES schools, which was attributed to greater focus on basic skills for high-stakes testing, lower levels of home access to technology, and a higher proportion of English language learners, at low-SES schools than at high-SES schools (Warschauer et al., 2004, pp. 582-584).

An examination of student barriers to online learning (Muilenburg \& Berge, 2005) provides some insight into potential sociocultural aspects of the Latino-White achievement gap at Costanza College, discussed in Chapter One. Muilenburg et al. analyzed surveys of 1056 respondents to an online instrument widely promoted using email lists of educators, online learning discussion forums, distance education conference 
attendees, and others. A factor analysis ranking the 47 barriers on the survey identified the single most important barrier to students learning online as a lack of social interaction (p. 35). Although only $0.4 \%$ of the respondents identified themselves as Hispanic $(n=4)$, the importance of social interaction in culturally relevant Latino education is well understood. Because of the way respondents were solicited, Muilenburg \& Berge did not capture the voices of Latino students themselves.

There has been little study of how subordinated student populations are faring in the online class environment. No peer-reviewed studies were located that compared the impact of online course delivery on the achievement gap between Latino and White students.

\section{Discussion}

California community college students do not do as well in online courses as they do in traditional, face-to-face classes (Nather, 2007), despite a broad consensus in the literature that online and face-to-face formats can produce comparable outcomes for students. As reported in Chapter 1, when Costanza College outcome data for 3,493 students, enrolled in transfer-level courses offered in both face-to-face and online formats, were disaggregated by ethnicity, White students had essentially the same outcome regardless of the format of the class. However, Latino students had dramatically less favorable outcomes in online courses than in face-to-face versions of the same courses, with a 23 percentage point lower success rate, grades that averaged two-thirds of a grade point lower, and withdrawal rates over twice as high. 
Additional work needs to be done to verify and validate the Costanza College findings across the California community college system, and to identify factors contributing to widening of the achievement gap between Latino and White students. A quantitative analysis of outcomes should be undertaken to determine the extent to which Costanza's results are replicated elsewhere, and to identify any additional gaps in achievement, that are exacerbated by online instruction, for other groups of students. Qualitative research with online Latino students should be conducted to identify factors that may widen the achievement gap in online courses.

The Internet has enabled new approaches to commerce, government, social structures, and politics - approaches that have revolutionized these fields. We shop and bank online, register our cars and pay our taxes, renew old relationships and forge new ones across vast geographies, and drive political change from the grassroots, overwhelming traditional power structures. The capacity for the Internet to democratize institutions, to level playing fields, and to accelerate progress and change cannot be overestimated. Educators must harness and direct this power to solve our most intransigent problems, and I believe the achievement gap surely tops this list. 


\section{Chapter Three: Methodology}

This study employed an explanatory mixed methods approach. The first phase of the study was a quantitative analysis of approximately 4.5 million student records of grades earned in California community college courses that were offered in both online and face-to-face formats between May 2005 and July 2009. The quantitative phase evaluated the relationship between the dependent variable, student outcome, expressed as the grade earned, and ethnicity, gender, and other available independent variables, for White and Latino students enrolled in either format of these courses. The second phase of the study was a qualitative analysis of the experiences of 10 Latino students, enrolled in online courses at Costanza College in the Fall 2010 semester.

A mixed methods approach was appropriate to address the research question, how enrollment in online classes impacts academic success for California Latino community college students, since both the size of any effects and the causes of those effects are of interest. Quantitative methods included comparisons of average grades and success rates, across a range of attributes, to provide a statistical assessment of effect sizes and significance. However, the underlying causes of these effects were best explored by listening to the voices of the students. Accordingly, qualitative methods were used to capture the students' perspective.

Based on the conceptual framework outlined in Chapter 1, the qualitative research with online Latino students focused on their perception of whether their online courses employed a humanizing pedagogy, based on relationships. As mentioned in Chapters 1 
and 2, relationships are central to effective teaching and learning with Latino students (Valenzuela, 1999; Solorzano \& Delgado-Bernal, 2001; Duncan-Andrade \& Morrell, 2008; Solorzano et al., 2005). If institutional adoption of online technology is indeed

driven by equivalency theory, leaving online classes largely devoid of the interactive, relational Web 2.0 features that could support new approaches to relational, socioculturally-relevant teaching and learning, then Latino students could find these classes frustrating and irrelevant, resulting in less favorable online outcomes for Latino students than for White students.

\section{Context}

The California community college system is the largest system of higher education in the country, consisting of 116 colleges in 72 districts, serving more than 2.5 million students each year, or around one quarter of all community college students nationwide. Approximately $5 \%$ of all instruction within the system is implemented as online classes, defined as those delivered primarily using the Internet, and this percentage continues to grow. As Table 4 illustrates, the student population is diverse, with White and Hispanic students comprising the two largest ethnic segments at $31.1 \%$ and $29.6 \%$ respectively. 
Table 4

2009-10 California Community College Enrollment by Ethnicity

\begin{tabular}{lrr}
\hline Ethnicity & Headcount & Percent \\
\hline African-American & 194,992 & $7.1 \%$ \\
American Indian/Alaskan Native & 17,786 & $0.6 \%$ \\
Asian & 306,210 & $11.1 \%$ \\
Filipino & 79,829 & $2.9 \%$ \\
Hispanic & 817,514 & $29.6 \%$ \\
Pacific Islander & 17,714 & $0.6 \%$ \\
Two or More Races & 35,280 & $1.3 \%$ \\
Unknown/Non-Respondent & 431,774 & $15.6 \%$ \\
White & 859,280 & $31.1 \%$ \\
\hline TOTAL & $2,760,379$ & $100.0 \%$ \\
\hline
\end{tabular}

Costanza College was selected as the site for the qualitative portion of this study because of the availability of online courses, the large Hispanic (28.4\%) segment of the student body, and the cooperation of faculty and administrators in providing access to student participants. Costanza was also recently designated a Title V Hispanic Serving Institution by the U.S. Department of Education.

\section{Role of the Researcher}

The researcher for this study was a face-to-face classroom instructor at Costanza College when the qualitative data was collected. Study participants were recruited from online classes in multiple academic disciplines, including subjects taught by the researcher. Though the researcher did not teach online classes, four of the qualitative study participants were enrolled in face-to-face courses taught by the researcher during the study semester, and three of these participants were also known by the researcher 
from prior classes. Accordingly, some participants may have volunteered to take part in the study because of their pre-existing relationship with the researcher.

\section{Ethics and Protection of Human Subjects}

Quantitative data were extracted from the statewide accountability reporting database in August 2010, using database queries developed with cooperation from the Management Information Systems group in the state Chancellor's office. Prior to providing data to the researcher, the records were anonymized by replacing personally identifiable elements with unrelated sequence numbers. The researcher then loaded the resultant anonymous records to a personal computer, which was used to perform the statistical analyses.

There was a risk of a potential loss of privacy to participants in the qualitative portion of the study. This risk was minimized by employing measures to protect the confidentiality of personally identifiable data, including (a) keeping contact information separate from interview records, with participants assigned a pseudonym known only to the researcher; (b) encrypting electronic data, including audio recordings and transcriptions of interviews, and storing the resulting files in password-protected directories of the researcher's computer; (c) personally producing transcriptions of audio recordings of interviews, replacing personally identifiable information with pseudonyms, and erasing raw recordings immediately following transcription; and (d) keeping all nonelectronic documentation containing personally identifiable information in a locked cabinet, inside of a locked office on the Costanza College campus. 
There was also a psychological risk to participants in the qualitative portion of the study, of anxiety or discomfort while discussing personal issues related to academic performance. To minimize this risk, interviews were conducted individually in a private office on the Costanza College campus. In addition, participants were informed that they could refuse to answer any question, stop the interview at any time, and withdraw from the study at any time. A consent form, outlining the nature and risks of the study, was signed by each participant.

\section{Quantitative Design and Analysis}

Quantitative data used for this study were student outcomes, reflected in the grade earned, for every White and Latino California community college student enrolled in a course that was offered in both online and face-to-face format, between May 2005 and July 2009. The source file for this dataset consisted of over 12 million student records, each containing the grade earned in the class, along with attributes descriptive of both the student and class taken. This file was imported into PASWStatistic 18.0 statistical analysis software, running on a Macintosh personal computer, where additional selections and processing were performed.

Records were restricted to White and Latino students, based on the self-identified ethnicity from their college application. Although most public reporting aggregates Latino students into the broader category of Hispanic, records used for this study included a more granular segmentation. Accordingly, the ethnicities selected for further analysis totaled 7,479,840 records, comprised of students who identified themselves as 
White $(4,273,900)$; Latino, South American $(83,574)$; Latino, Central American (241,002); Latino, Mexican, Mexican-American, Chicano (1,905,390); or Latino, not specific $(975,974)$.

Outcomes for courses offered in both online and face-to-face formats over the full time period were selected to produce the original source file, thus potentially including courses that may have been offered in only a single format during a particular semester. This study, however, sought to make the most valid comparisons possible between formats, by limiting the analyses to those instances where students were presented with a choice of formats during the semester they took the course, at the college they attended. A complex SPSS procedural program was created to restrict selection to courses that met this requirement, resulting in a reduced dataset of 4,719,415 records. An additional 93,268 records were eliminated from consideration because the type of instruction did not meet the criteria online or face-to-face, resulting in a dataset of 4,626,147 records.

\section{Grades.}

Student grades were provided in a text field within each record, with the range of values dependent on the grading scheme and codes employed by each individual college. For example, schools record "incomplete" grades using a variety of one- or two-letter designations. Fortunately, non-standard designations and incompletes, while difficult to interpret, represented an insignificant $3.3 \%$ of the records in the dataset. These records were therefore eliminated, resulting in a final file for analysis containing $4,472,736$ records. 


\section{Independent variables.}

In addition to the student outcome of grade earned, each record contains independent variables descriptive of the student and of the class taken. Student attribute variables evaluated for this study included ethnicity, gender, and educational goal. Class attributes evaluated included transfer status, occupational classification, and basic skills status. Comparisons of White and Latino student outcomes were made across student and class attributes, based on the average of grades earned, and on student success rates. Complete definitions of student and class attributes are provided in Appendix 2.

\section{Calculated average grade.}

The average of the grades earned for a group is a common measure of outcome. In fact, a student's grade point average (GPA) is the key criteria for degree attainment, academic standing, and transfer to a four-year college or university.

To calculate averages of grades earned, the letter grades in the final file were converted to a numeric format using a standard 4-point scale $(\mathrm{A}=4.0, \mathrm{~B}=3.0, \mathrm{C}=2.0$, $\mathrm{D}=1.0, \mathrm{~F}=0.0$ ) with pluses and minuses one third of a grade point above or below their respective letter-grade values. Students who withdrew from a class within the first two weeks of the term were not included in the source file, so a grade of "W" represented a student who failed to successfully complete the class, and accordingly, was converted to a numeric 0.0 for this analysis. Also, the $1.6 \%$ of the records containing a "P" for "pass" were scored as a 2.0 , and the $0.7 \%$ of the records containing an "NP" for "not pass" were scored as a 0.0 . 
Differences between average grades were first calculated as a raw difference, and then converted to an effect size by expressing the difference as a multiple of the combined standard deviation. Cohen's (1992) classification is often used to establish the threshold for a meaningful effect size at 0.20 standard deviations With grades, however, effect sizes below this threshold should still be considered relevant, since grade cutoffs for transfer or graduation milestones are quite rigid. Accordingly, differences are characterized as (1) minor, for effect sizes below 0.10 standard deviations; (2) moderate, for effect sizes of 0.10 to 0.20 standard deviations; and (3) meaningful, for effect sizes greater than 0.20 . Differences are only considered to be statistically significant if the pvalue is less than 0.001 , since the sample sizes are extraordinarily large.

\section{Success rates.}

Two new fields were added to each record to enable analysis of student success rates, the percentage of students who succeed in completing a class or group of classes, with success coded as a 1.0 and lack of success coded as a 0.0 . First, a field labeled "CCC Success" was added to each record, defining success as earning a passing, "P" or "C" or better, grade. This corresponds to the standard measure of success in the California community college system (Woodruff \& Perry, 2008), and represents the grade generally necessary to satisfy the requirements to transfer to the CSU system. Each community college in California reports this student success rate as part of the Accountability Reporting for California Community Colleges (ARCCC) system (Sengupta \& Jepsen, 2006). Second, to address the key equity issue, discussed in Chapters 2, of Latino 
students' underrepresentation among University of California transfer students, a field for "UC Success" was added to each record. Since the U.C. system, with a few exceptions, requires students to earn a 3.0 grade point average, "C" grades should not be considered success for a U.C. transfer student. Accordingly, for this field, success is defined as earning a "B" or better grade in the class.

Coding success as a numeric 1.0 and lack of success as a numeric 0.0 facilitates calculation of success rates, since the percentage of successful students will be equal to the arithmetic average of the values recorded in these two fields. Comparisons between success rates were expressed as the difference in rate in percentage points, with statistical significance evaluated using a z-test for differences in proportions.

Qualitative Design and Analysis

The qualitative research explored student attitudes and cultural tenets that may impact Latino student success in online classes. Ten Latino/a students were interviewed during the first two weeks of the semester, at the $8^{\text {th }}$ week, and after the semester ended. Participants in the qualitative portion were Latino/a students, age 18 or older, selfselected from among students who registered for an online section of a course offered during the Fall 2010 semester at Costanza College.

\section{Participant recruitment.}

Study participants were recruited using a multistep process. First, instructors scheduled to teach at least one online class were sent an email, three weeks prior to the first day of classes, explaining the purpose of the study and asking for a list of email 
addresses of their enrolled students. Fourteen instructors were solicited, teaching courses in Anthropology, Business, Communications, English, Political Science, Psychology, and Sociology. These instructors' combined online enrollment totaled 1,604 students, with two Business instructors representing nearly $40 \%$ of this enrollment. Four instructors representing 703 enrolled students agreed to participate, including these two Business instructors, and one instructor each from Anthropology and English. When duplicate email addresses for students enrolled in more than one online class were eliminated, a final list of 529 students was available for solicitation.

These 529 students were sent an email during the week before the semester began. Although ethnicity information for these students was not available to the researcher, it is reasonable to expect that Latino students were represented at approximately their $20 \%$ proportion of online enrollments, thus providing a pool of just over 100 potential Latino participants among the students receiving the email. The email included (a) a description of the study and its purpose; (b) criteria for participation, including the requirement that the student self-identify their ethnicity as Latino; and (c) instructions on how to volunteer to participate. Thirteen Latino/a students replied via email, indicating a willingness to participate, and ten of these students signed consent forms to become study participants.

\section{Participant attributes.}

The ten Latino/a students who participated in the qualitative portion of the study provided a relatively diverse representation of Latino community college students. All participants had many years of experience using computers and the Internet. There were 
four Latinos and six Latinas, with ages ranging from 19 to 38 years old. Two single mothers participated, two other participants were married with children, and the rest were single. Educational attainment ranged from a first-year college student to a masters' degree holder, returning to school for a career change. Eight of the participants had taken at least one online class prior to their current online enrollment.

\section{Data collection.}

Each participant was interviewed three times during Fall 2010. The first interviews were conducted during the first two weeks of the semester, and were focused on building a trusting relationship between participants and the researcher, learning their rationale for choosing an online section over a face-to-face section, and understanding participants' expectations of their online classes. Second interviews, to review their online experiences partway through the semester, were conducted during the seventh and eighth week of the semester. The third and final interviews were conducted during finals week, after instruction for the semester had ended. Although all ten participants completed the second interview, only six participants completed the third and final interview.

Interviews were digitally recorded on the researcher's personal computer, with a backup recording created on the researcher's cellular telephone. Once verbatim transcripts of the interviews had been created, the recordings were erased. 
Qualitative analysis.

Text searches were conducted to identify qualitative data with potential explanatory value relevant to the quantitative results, and to gage the extent to which relationships among students and between students and instructors mediated success for study participants. When relevant content was located, it was reviewed for additional search constructs to be used for branching searches. From this analysis factors influencing online academic performance of study participants were identified. 


\section{Chapter Four: Report of Findings}

This research explored how enrollment in online classes impacts academic success for California's Latino community college students. The quantitative portion of the study revealed the extent to which the Costanza College effects, outlined in Chapter 1, are found throughout the California community college system. The qualitative portion explored Latino student understanding and experiences of relationships in their education, and particularly in their online classes.

\section{Quantitative Findings}

The dataset used for these analyses contained records of the grade earned in a California community college course between May 2005 and July 2009. Courses were limited to those offered in both online and face-to-face formats, during the semester in which the class was taken, and on the campus the student attended, resulting in 4,472,736 valid records. Student attributes evaluated included ethnicity, gender, and goal. Class attributes evaluated included transfer status, occupational classification, and vocational status. Because of the large overall number of records, even the smallest analytical units involved thousands of relevant records. Accordingly, statistical significance is only reported for p-values less than .001 . The focus of analysis is on relative effect sizes, and how meaningful the differences are across the reported attributes.

\section{Online enrollments.}

Students who enrolled in the online section of their course were different than those who chose face-to-face sections, across the attributes of ethnicity, gender, and 
educational goal. Students with occupational and vocational goals were much more likely to enroll in online classes than in face-to-face classes. Students enrolled at a 4-year college or university, while simultaneously taking a community college course, were also more likely to choose an online class. Online classes also had a higher proportion of White students and of females than face-to-face classes, while Latino students and males preferred to enroll in face-to-face classes. Students working toward their high school diploma were also less likely to enroll in online classes, as were those who were still formulating their career or educational plans.

The courses that students preferred to take in an online format, when a choice was offered, largely paralleled the goals of the students. Occupational courses were far more likely to be taken in an online format than face-to-face. Non-transferable, degree specific, and basic skills courses were all about half as likely to be taken in an online format than face-to-face. Finally, courses providing transfer credit to both the UC and CSU systems showed no student preference in course format, while courses that transferred only to the CSU system were more likely to be taken in an online format than face-to-face.

The online penalty.

Overall, students who chose an online class instead of a face-to-face class paid a penalty for that choice: The outcome was worse in online classes than in face-to-face sections of the same course, offered at the same school, during the same semester. When data were viewed at the aggregate level, students in online classes had success rates of $58.4 \%$, compared to success rates of $65.6 \%$ in face-2-face classes, an online penalty of 
7.2 percentage points. The average grade earned, on a 4-point scale, was 2.02 , or passing, in face-to-face classes, and 1.92, or not passing, in online classes, with a minor effect size of -0.06 standard deviations $(\mathrm{p}<.001)$.

Average grade by student attributes.

In Table 5, when the data are disaggregated by student goal, without regard to other student attributes of gender and ethnicity, the online penalty ranges from +0.05 Table 5

Online vs. Face-to-face Average Grade by Student Goal

\begin{tabular}{lccc} 
Student Goal $(\mathrm{n})$ & Face-to-face & Online & Effect Size \\
\hline Acquire job skills $(144,248)$ & 2.08 & 2.16 & $+0.05^{*}$ \\
4-year students $(47,820)$ & 2.23 & 2.30 & $+0.05^{*}$ \\
Update job skills $(67,474)$ & 2.30 & 2.33 & +0.02 \\
Vocational certification 62,584) & 2.08 & 2.10 & +0.01 \\
Maintain license $(49,690)$ & 2.00 & 2.00 & 0.00 \\
2-year Associates degree $(233,638)$ & 2.00 & 1.99 & -0.01 \\
2-year vocational degree (65,323) & 2.03 & 1.99 & -0.02 \\
Noncredit to credit $(1,111)$ & 1.90 & 1.86 & -0.03 \\
Educational development $(114,791)$ & 2.24 & 2.19 & $-0.03^{*}$ \\
Basic skills (36,722) & 2.09 & 2.03 & -0.04 \\
Formulate plans $(112,585)$ & 2.02 & 1.95 & $-0.04^{*}$ \\
Undecided (668,021) & 1.96 & 1.85 & $-0.07^{*}$ \\
Transfer with AA degree $(1,780,808)$ & 2.00 & 1.83 & $-0.11^{*}$ \\
Transfer without AA degree $(515,962)$ & 2.12 & 1.93 & $-0.12^{*}$ \\
HS diploma or GED $(109,824)$ & 2.03 & 1.79 & $-0.15^{*}$ \\
\hline
\end{tabular}
$*=p<.001$ 
standard deviations, to -0.15 standard deviations. In other words, for some student goals, the overall average grade in the online sections is slightly higher than in the face-to-face sections, and for other student goals, slightly lower. The results in Table 5 seem to be generally in accordance with the consensus discussed in Chapter 2, that online classes are neither better, nor worse, than face-to-face classes.

However, disaggregation of the data in Table 5 by ethnicity and gender reveals a starkly different picture. For example, from Table 5, students with a goal to update job skills had a 2.33 aggregate average grade in their online classes, slightly higher $(p=.04)$ than the 2.30 aggregate average grade earned in face-to-face classes taken by students with the same goal. Table 6 disaggregates these data, by ethnicity and gender.

Table 6

Face-to-face vs. Online Average Grade, Goal to Update Job Skills

\begin{tabular}{llccc} 
& & Face-to-face & Online & Effect Size (SD) \\
\cline { 2 - 4 } Latino & Latino & 1.92 & 1.95 & +0.02 \\
& Latina & 2.13 & 1.91 & $-0.14^{*}$ \\
& Total Latino/a & 2.06 & 1.92 & $-0.09 *$ \\
\cline { 2 - 5 } White & Male & 2.31 & 2.40 & +0.05 \\
& Female & 2.54 & 2.49 & -0.04 \\
& Total White & 2.45 & 2.46 & +0.01 \\
\cline { 2 - 5 } & Male & $0.24^{*}$ & $0.28^{*}$ & $+16.7 \%$ \\
Latino-White Gap (SD) & Female & $0.26^{*}$ & $0.36^{*}$ & $+38.5 \%$ \\
& Total & $0.24^{*}$ & $0.34^{*}$ & $+41.7 \%$ \\
\hline
\end{tabular}

$n=67,474 ; *=p<.001$ 
While the aggregate results from Table 5 implied that students with the goal to update job skills would do slightly better in online classes, disaggregation reveals that this is true only for White males, at a significance level $(p=.02)$ that does not meet the study threshold of .001. However, there are statistically significant, meaningful differences in outcomes when comparing Latino and White students. In the case of students with a goal to improve job skills, White students had no online penalty, while Latinas had a moderate online penalty of 0.14 standard deviations, which resulted in a combined Latino/a minor online penalty of 0.09 standard deviations. Accordingly, the achievement gap between Latino and White student performance, expressed in average grade, was exacerbated in online classes, increasing $41.7 \%$ from a meaningful 0.24 standard deviations to 0.34 standard deviations.

Table 7 provides a comparison of face-to-face and online average grades, broken out by ethnicity and gender, for all goals combined. For every combination of ethnicity and gender, there is a statistically significant $(\mathrm{p}<.001)$ online penalty for students. Because this online penalty is minor, at 0.08 standard deviations, for White students, and moderate, at 0.13 standard deviations for Latino students, the Latino-White achievement gap, measured by average grade was exacerbated in online classes, by $44.0 \%$, from a meaningful 0.25 standard deviations in face-to-face classes, to 0.36 standard deviations in online classes. 
Table 7

Face-to-face vs. Online Average Grades, All Goals

\begin{tabular}{llccc} 
& & Face-to-face & Online & Effect Size (SD) \\
\cline { 2 - 4 } Latino & Latino & 1.73 & 1.58 & $-0.10^{*}$ \\
& Latina & 1.87 & 1.61 & $-0.16^{*}$ \\
& Total Latino/a & 1.81 & 1.60 & $-0.13^{*}$ \\
\cline { 2 - 5 } White & Male & 2.08 & 1.97 & $-0.07^{*}$ \\
& Female & 2.29 & 2.13 & $-0.10^{*}$ \\
& Total White & 2.19 & 2.07 & $-0.08^{*}$ \\
\cline { 2 - 5 } & Male & $0.23^{*}$ & $0.31^{*}$ & $+34.8 \%$ \\
Latino-White Gap (SD) & Female & $0.28^{*}$ & $0.40^{*}$ & $+42.9 \%$ \\
& Total & $0.25^{*}$ & $0.36^{*}$ & $+44.0 \%$ \\
\hline$n=4,472,736 ; *=p<.001$ & & &
\end{tabular}

The online penalty in average grade for students with vocational goals is less severe than for students planning to transfer to a 4-year college or university. In fact, as Table 8 reveals, there was essentially no online penalty in average grade for vocational students, other than a moderate 0.12 standard deviation penalty for Latinas, resulting in a minor 0.08 standard deviation penalty for combined Latino/a vocational students. Since there was no difference at all in average grade between White, vocational, online and face-to-face students, the impact of the moderate Latina online penalty was to increase the Latino-White achievement gap in average grade among vocational students by $28.6 \%$, from a meaningful 0.28 standard deviations to 0.36 standard deviations. 
Table 8

Face-to-face vs. Online Average Grades, Transfer and Vocational Goals

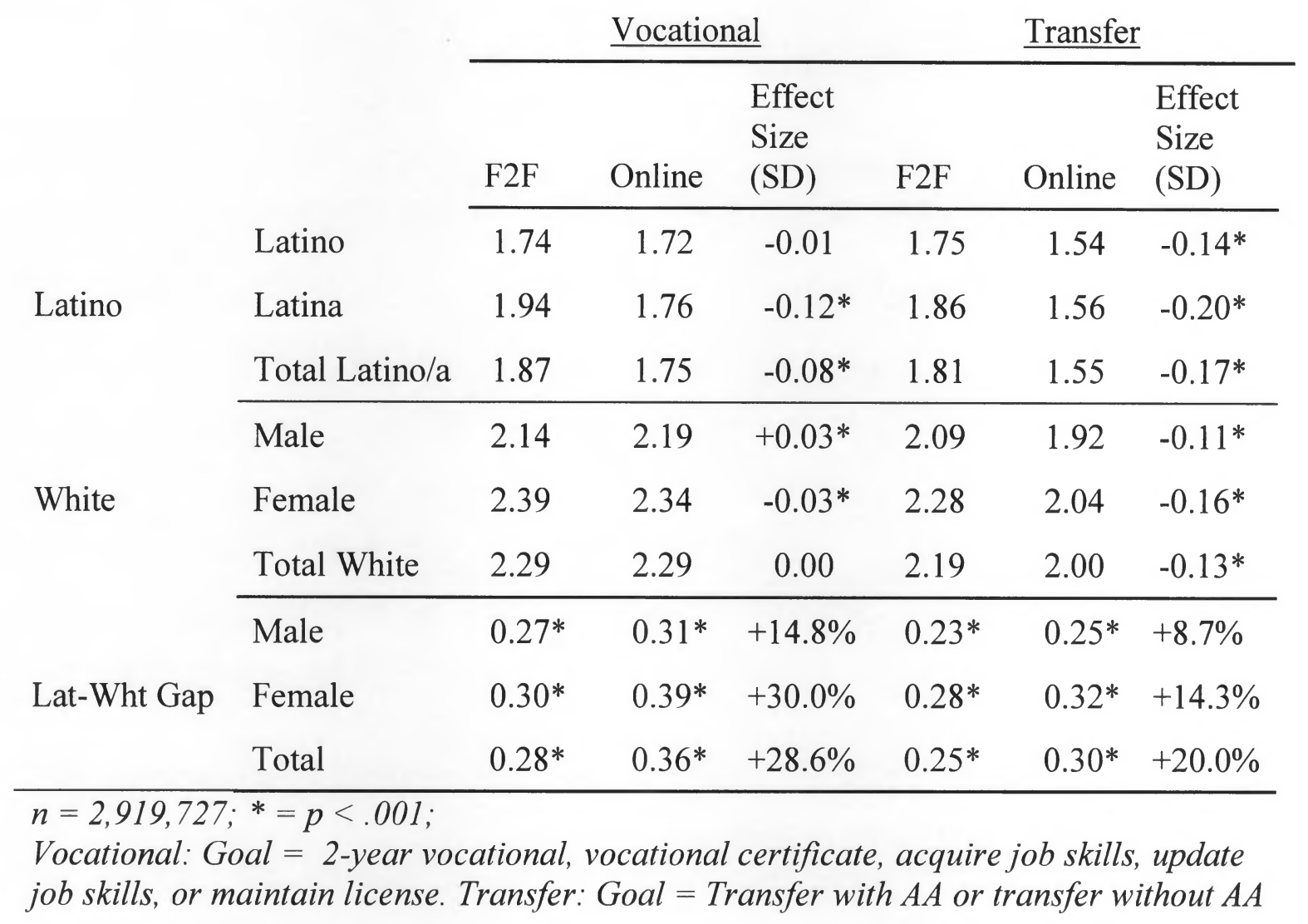

In the far right column of Table 8, all students with a goal to transfer experienced an online penalty. The online penalty in average grade for White transfer student was moderate, at 0.13 standard deviations, while a meaningful online penalty of 0.20 standard deviations for Latinas resulted in a larger, 0.17 standard deviation online penalty for Latino/a students. Accordingly, the Latino-White achievement gap among transfer students was exacerbated in online classes, growing by $20 \%$, from 0.25 standard deviations to 0.30 standard deviations. 
Underprepared Latino students experienced the greatest online penalty in average grade. Table 9 shows a comparison of face-to-face and online average grade, broken out by ethnicity and gender, for underprepared students, defined as students with goals to improve their basic skills, or to earn a high school diploma or GED. Both Latino and Latina underprepared students recorded meaningful effect sizes, with online average grade penalties of 0.20 standard deviations and 0.25 standard deviations, respectively. Underprepared White students recorded moderate online average grade penalties approximately equal to those recorded by White transfer students, with a combined male and female online penalty of 0.13 standard deviations. Because the online penalty of 0.20 standard deviations for underprepared Latino students was greater by $53.8 \%$ than the Table 9

Face-to-face vs. Online Average Grades, Underprepared Students

\begin{tabular}{|c|c|c|c|c|}
\hline & & Face-to-face & Online & Effect Size (SD) \\
\hline \multirow{3}{*}{ Latino } & Latino & 1.73 & 1.51 & $-0.20^{*}$ \\
\hline & Latina & 1.92 & 1.52 & $-0.25^{*}$ \\
\hline & Total Latino/a & 1.84 & 1.52 & $-0.20^{*}$ \\
\hline \multirow{3}{*}{ White } & Male & 2.10 & 1.92 & $-0.11^{*}$ \\
\hline & Female & 2.32 & 2.09 & $-0.14 *$ \\
\hline & Total White & 2.23 & 2.03 & $-0.13^{*}$ \\
\hline \multirow{3}{*}{ Latino-White Gap (SD) } & Male & $0.23 *$ & $0.26^{*}$ & $+13.0 \%$ \\
\hline & Female & $0.25^{*}$ & $0.36^{*}$ & $+44.0 \%$ \\
\hline & Total & $0.24^{*}$ & $0.32 *$ & $+33.3 \%$ \\
\hline
\end{tabular}

$n=146,546 ; *=p<.001 ;$ Underprepared students are those with a goal of improving basic skills or obtaining a high school diploma or GED 
online penalty of 0.13 standard deviations for underprepared White students, the LatinoWhite achievement gap in average grade was exacerbated by $33.3 \%$ in online classes over face-to-face classes, from 0.24 standard deviations to 0.32 standard deviations.

\section{Success rates by student attributes.}

A comparison between the UC success rate, the percentage of students that earned a B or better in their classes, and the standard reported community college success rate, the percentage of students that earned a $\mathrm{C}$ or better in their classes, is presented in Table 10 , broken down by ethnicity and gender. The online penalty in UC success rates was Table 10

Face-to-face vs. Online Success Rate (\%), All Goals

\begin{tabular}{|c|c|c|c|c|c|c|c|}
\hline & & \multicolumn{3}{|c|}{ UC Success } & \multicolumn{3}{|c|}{ CC Success } \\
\hline & & $\mathrm{F} 2 \mathrm{~F}$ & $\mathrm{OL}$ & $+/-$ & $\mathrm{F} 2 \mathrm{~F}$ & $\mathrm{OL}$ & $+/-$ \\
\hline \multirow{3}{*}{ Latino } & Latino & 35.9 & 35.6 & -0.3 & 56.9 & 49.4 & $-7.5^{*}$ \\
\hline & Latina & 39.9 & 36.2 & $-3.7^{*}$ & 60.6 & 50.4 & $-10.2^{*}$ \\
\hline & Total Latino/a & 38.2 & 36.0 & $-2.2^{*}$ & 59.1 & 50.1 & $-9.0 *$ \\
\hline \multirow{3}{*}{ White } & Male & 46.9 & 46.4 & $-0.5^{*}$ & 65.5 & 59.6 & $-5.9^{*}$ \\
\hline & Female & 53.4 & 50.6 & $-2.8^{*}$ & 70.1 & 63.4 & $-6.7^{*}$ \\
\hline & Total White & 50.4 & 49.2 & $-1.2^{*}$ & 68.0 & 62.0 & $-6.0^{*}$ \\
\hline \multirow{3}{*}{ Latino-White Gap } & Male & $11.0^{*}$ & $10.8^{*}$ & $+0.2^{*}$ & $8.6^{*}$ & $10.2^{*}$ & $-1.6^{*}$ \\
\hline & Female & $13.5^{*}$ & $14.4^{*}$ & $-0.9^{*}$ & $9.5^{*}$ & $13.0^{*}$ & $-3.5^{*}$ \\
\hline & Total & $12.2^{*}$ & $13.2 *$ & $-1.0^{*}$ & $8.9^{*}$ & $11.9^{*}$ & $-3.0^{*}$ \\
\hline
\end{tabular}


not statistically significant for Latino males, and small for all other combinations of ethnicity and gender, with the largest impact, 3.7 percentage points, for Latinas.

The online penalty in the community college reported success rate was much larger, ranging from 5.9 percentage points for White males, to 10.2 percentage points for Latinas. In addition, the community college success rate online penalty was 6.0 percentage points for White students of both genders, and 50\% larger, at 9.0 percentage points for Latino students of both genders. Accordingly, the Latino-White achievement gap, expressed by the community college success rate, was exacerbated by $33.7 \%$ in online classes, from a face-to-face gap of 8.9 percentage points, to an online gap of 11.9 percentage points.

An evaluation in Table 11 of the community college success rate by ethnicity and gender, broken out into rates for students with vocational and transfer goals, closely parallels the vocational student findings, measured by average grade, from Table 7 . The community college success rate online penalty for vocational students was below four percentage points for all except Latinas, who experienced an online penalty of 8.2 percentage points. This negative outcome for Latinas contributed to a combined male and female Latino community college success rate online penalty of 6.5 percentage points, and a widening of the Latino-White community college success rate gap by $48.4 \%$, from 9.1 percentage points in face-to-face classes, to 13.5 percentage points in online classes. 
Table 11

Face-to-face vs. Online Success Rates (\%), Transfer and Vocational Goals

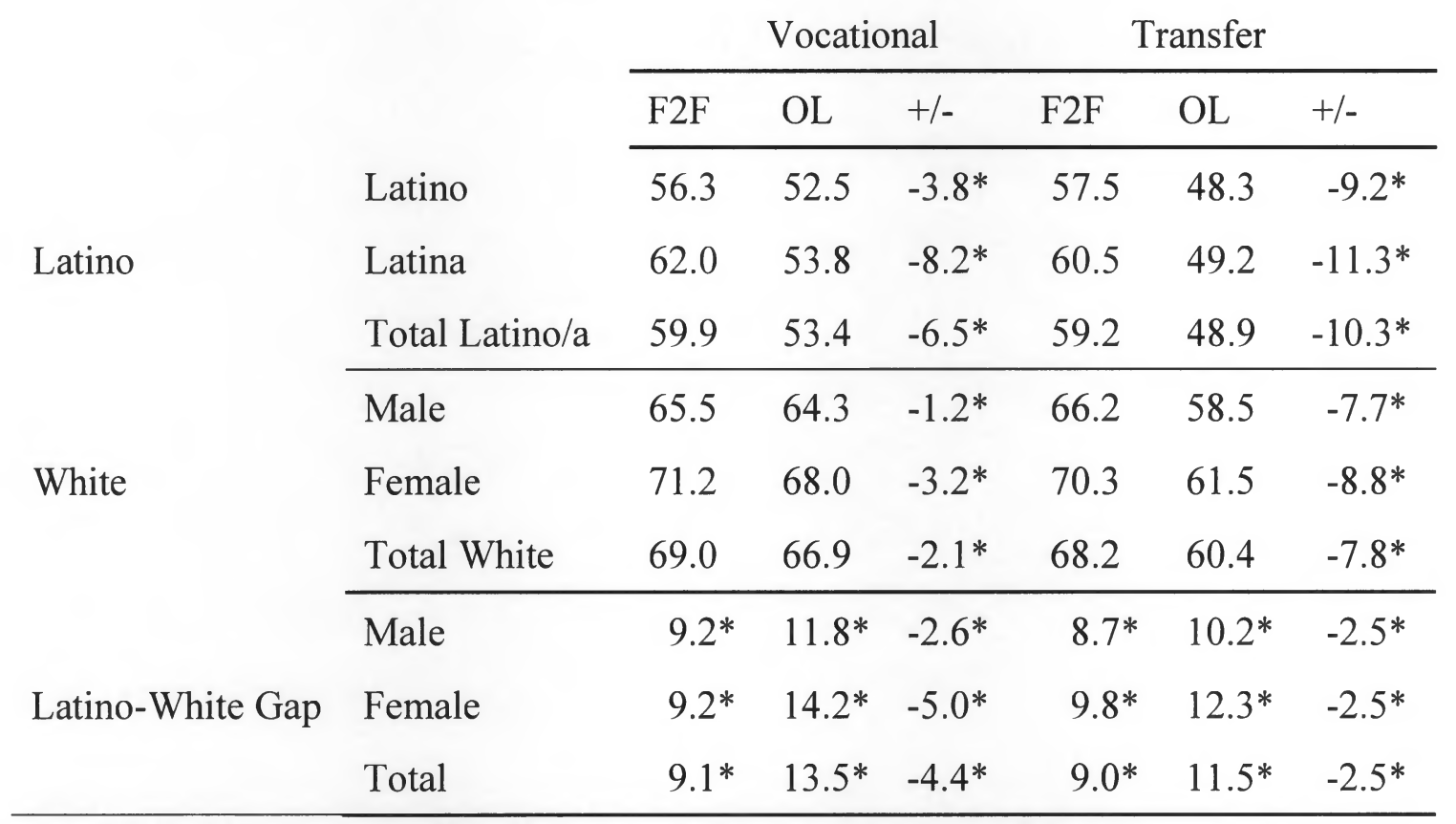

$n=2,919,727 ; *=p<.001 ;$ Vocational: Goal $=2$-year vocational, vocational certificate, acquire job skills, update job skills, or maintain license; Transfer: Goal = Transfer with AA or transfer without AA

The online community college success rate penalty for transfer students, in the far right column of Table 11, was higher for every combination of ethnicity and gender than was the online community college success rate penalty for vocational students. The greatest penalty was recorded for Latina students, with a community college success rate that fell by 10.3 percentage points, from $60.5 \%$ in face-to-face classes to just $49.2 \%$ in online classes. Further, because the online penalty among transfer students was greater for Latino/a students than for White students, the Latino-White achievement gap, 
expressed in the community college success rate, was exacerbated in online classes by 2.5 percentage points.

Community college success rates were also calculated for underprepared students, broken out by ethnicity and gender, and presented in Table 12 . The greatest online penalty among underprepared students was for Latina students, where the online Table 12 Face-to-face vs. Online Success Rates (\%), Underprepared Students

\begin{tabular}{llccc} 
& & Face-to-face & Online & $+/-$ \\
\cline { 2 - 4 } Latino & Latino & 56.8 & 47.4 & $-9.4^{*}$ \\
& Latina & 61.7 & 48.1 & $-13.6^{*}$ \\
\cline { 2 - 4 } White & Total Latino/a & 59.8 & 47.9 & $-11.9^{*}$ \\
\cline { 2 - 5 } & Male & 66.0 & 58.1 & $-7.9^{*}$ \\
& Female & 70.1 & 62.4 & $-7.7^{*}$ \\
\multirow{3}{*}{ Latino-White Gap } & Total White & 68.8 & 60.9 & $-7.9^{*}$ \\
\cline { 2 - 5 } & Male & $9.2^{*}$ & $10.7^{*}$ & $-1.5^{*}$ \\
& Female & $7.1^{*}$ & $14.3^{*}$ & $-7.2^{*}$ \\
& Total & $9.0^{*}$ & $13.0^{*}$ & $-4.0^{*}$ \\
\hline
\end{tabular}

$n=146,546 ; *=p<.001 ;$ Underprepared students are those with a goal of improving basic skills or obtaining a high school diploma or GED

community college success rate was just $48.1 \%$, or 13.6 percentage points below the $61.7 \%$ success rate of underprepared Latina students enrolled in face-to-face classes. Underprepared face-to-face White students had a community college success rate of $68.8 \%$, which was 9.0 percentage points higher than the $59.8 \%$ success rate of 
underprepared Latino students. Because the success rate online penalty for underprepared White students was smaller, at 7.9 percentage points, than the online penalty of 11.9 percentage points incurred by underprepared Latino students, the community college success rate achievement gap between Latino and White students was exacerbated $44.4 \%$ in online classes, by 4.0 percentage points.

Outcomes by course attributes.

For a variety of reasons, students sometimes take courses that are not aligned with their goal. Students with a goal to transfer had $14.3 \%$ of their enrollments in courses that were classified as non-transfer status. Students with vocational goals had $63.6 \%$ of their enrollments in courses that were not classified as occupational. Underprepared students, with goals of improving basic skills, or earning a high school diploma or GED, had $96.8 \%$ of their enrollments in courses that were not classified as basic skills courses. These disparities prompted examination of outcomes for students enrolled in classes that aligned with their stated goal: Transfer students in transfer classes, vocational students in occupational classes, and underprepared students in basic skills classes.

Table 13 provides a comparison of face-to-face and online average grade, broken out by ethnicity and gender, for students with a goal to transfer, and who were enrolled in courses categorized as transfer-level courses. Latina transfer students in transfer classes experienced a meaningful online penalty in average grade of 0.21 standard deviations, contributing to a moderate combined Latino/a online penalty of 0.19 standard deviations. 
Table 13

Face-to-face vs. Online Average Grade, Transfer Goals in Transfer Courses

\begin{tabular}{llccc} 
& & Face-to-face & Online & Effect Size (SD) \\
\cline { 2 - 4 } Latino & Latino & 1.82 & 1.57 & $-0.16^{*}$ \\
& Latina & 1.94 & 1.60 & $-0.21^{*}$ \\
& Total Latino/a & 1.89 & 1.59 & $-0.19^{*}$ \\
\cline { 2 - 5 } White & Male & 2.17 & 1.96 & $-0.13^{*}$ \\
& Female & 2.37 & 2.09 & $-0.17^{*}$ \\
& Total White & 2.27 & 2.04 & $-0.14^{*}$ \\
\cline { 2 - 5 } & Male & $0.22^{*}$ & $0.24^{*}$ & $+9.1 \%$ \\
Latino-White Gap (SD) & Female & $0.27^{*}$ & $0.31^{*}$ & $+14.8 \%$ \\
& Total & $0.24^{*}$ & $0.28^{*}$ & $+16.7 \%$ \\
\hline
\end{tabular}

$n=1,968,200 ; *=p<.001$

White transfer students in transfer classes also experienced an online average grade penalty of 0.13 standard deviations for males, and 0.17 standard deviations for females. For transfer students in transfer classes, because the combined gender White online average grade penalty, at 0.14 standard deviations, was smaller than the Latino online penalty, the Latino-White achievement gap was exacerbated in online classes by $16.7 \%$, from 0.24 standard deviations to 0.28 standard deviations. These outcomes closely mirror transfer student outcomes without restricting the courses to transfer-level courses, as summarized in Table 7.

Analysis of outcomes in average grade for vocational students was conducted with an additional restriction, limiting the courses to those with an occupational 
designation. The results, summarized in Table 14, matched the general pattern for vocational students across all courses, as reported in Table 8 , though with marginally higher average grades across all combinations of ethnicity and gender. When restricted to occupational classes, vocational students still saw the greatest online penalty for Latinas, at a moderate 0.14 standard deviations, which was primarily responsible for a $25.6 \%$ exacerbation of the Latino-White achievement gap in average grade, from a meaningful 0.39 standard deviations in face-to-face classes to 0.49 standard deviations in online classes.

Table 14

Face-to-face vs. Online Average Grade, Vocational Goals in Occupational Courses

\begin{tabular}{llccc} 
& & Face-to-face & Online & Effect Size (SD) \\
\cline { 3 - 5 } Latino & Latino & 1.91 & 1.86 & -0.03 \\
& Latina & 2.14 & 1.91 & $-0.14^{*}$ \\
\multirow{3}{*}{ White } & Total Latino/a & 2.05 & 1.89 & $-0.10^{*}$ \\
\cline { 2 - 5 } & Male & 2.31 & 2.27 & -0.03 \\
& Female & 2.53 & 2.43 & $-0.06^{*}$ \\
\multirow{2}{*}{ Latino-White Gap (SD) } & Female & 2.44 & 2.38 & $-0.04^{*}$ \\
\cline { 2 - 5 } & Total White & $0.40^{*}$ & $0.41^{*}$ & $+2.5 \%$ \\
\hline
\end{tabular}

$n=141,798 ; *=p<.001$

Outcomes in average grade were also analyzed for underprepared students enrolled in basic skills classes. Table 15 shows that there were no statistically significant 
differences in outcome, across ethnicity or gender, for underprepared students enrolled in basic skills classes.

Table 15

Face-to-face vs. Online Average Grade, Underprepared Students in Basic Skills Courses

\begin{tabular}{llccc} 
& & Face-to-face & Online & Effect Size (SD) \\
\cline { 2 - 4 } Latino & Latino & 1.44 & 1.52 & +0.05 \\
& Latina & 1.65 & 1.58 & -0.05 \\
& Total Latino/a & 1.57 & 1.56 & -0.01 \\
\cline { 2 - 5 } White & Male & 1.52 & 1.38 & -0.09 \\
& Female & 1.75 & 1.80 & +0.03 \\
& Total White & 1.66 & 1.66 & 0.00 \\
\cline { 2 - 5 } & Male & 0.05 & -0.09 & \\
Latino-White Gap (SD) & Female & 0.07 & 0.15 & \\
& Total & 0.06 & 0.07 & \\
\hline
\end{tabular}

$n=4,763 ; *=p<.001 ;$ Underprepared students are those with a goal of improving basic skills or obtaining a high school diploma or GED

\section{Summary of quantitative findings.}

Disaggregation of the data revealed an online penalty for most combinations of ethnicity and gender, with outcomes for students enrolled in online classes worse than outcomes for students enrolled in face-to-face classes. In addition, because this online penalty was greater for Latino students than for White students, the Latino-White achievement gap was exacerbated in online classes, with the most dramatic effect found among transfer students. With vocational students, there was essentially no online penalty 
found for males, Latino or White. However, because the online penalty among female vocational students was greater for Latinas than for White females, The Latino-White achievement gap was also exacerbated with vocational students, in online classes.

Underprepared students, enrolled in basic skills classes, were the only students for whom no online penalty was observed. In fact, this group of students experienced no significant differences in outcome, either between face-to-face and online classes, or between Latino and White ethnicities.

\section{Qualitative Findings}

Findings for the qualitative portion of the study are presented by first profiling each participant, then reporting a synthesis of their responses on the topics discussed in the interviews. Topics included descriptions of good and bad classes they had taken in the past; expectations expressed at the beginning of the semester, about the online class they had enrolled in; and their experience, partway through the semester and at the end of the semester, of their online class. For each topic, the focus of the interview was on the relationships, both between student and instructor, and among students, that developed in the class.

\section{Participant backgrounds.}

The ten participants profiled here self-selected for this study, and were not intended to represent a statistically valid sample. Each participant also had the choice, to take their course in either an online or face-to-face format. Since they chose the online format, they may have been more comfortable with computers and the Internet than 
Latino students who chose face-to-face classes. Other than this factor, the participants seemed fairly typical of a broad cross section of California Latino community college students, with diversity across age and gender. Names have been changed to protect the identity of the students.

Gerardo started at the community college four years ago, right after graduating from a local high school. He only took a few classes in the beginning, but recently became a full time student, planning to transfer to a 4-year school. Ethnically, Gerardo identified himself as Hispanic, not Caucasian, though his father was Spanish and his mother Cuban. His first language was Spanish, and he always found school a little difficult because of that. Gerardo felt that his physical appearance and nickname may have helped him assimilate, stating, "I go by George, I look semi-white, so I never got the feeling that I was treated differently."

Miguel was a 19-year-old male, in his first year of college. He first used a computer in elementary school, and had an uncle who "made sure my mom had a computer because he thought they were so necessary." His father was White and his mother Mexican, and he found his ethnic identity slightly ambiguous: “I couldn’t identify myself with one race because I feel that would be excluding ..." Miguel explicitly avoided consideration of race, saying, "it's not one of the things that's on my mind where I identify myself with a certain crowd."

$\underline{\text { Helena }}$ attended a CSU school for 3 years after high school, as a math major, before changing her goal to nursing and moving to the community college. Ethnically, 
she self-identified as either White, or biracial Hispanic/White. More specifically, she was "3/8ths Mexican and $1 / 8^{\text {th }}$ Native American." Because she could present as White, Helena believed she got the advantages of both ethnicities: "People will treat me like I am White but when they find out that I have a Hispanic heritage, sometimes I get a little bit more of a preferential [treatment]. Scholarships, for example, I get that advantage."

$\underline{\text { Isaac }}$ was a 27-year-old married man with one small child. He identified himself as Mexican-American, and believed that he was treated differently because of that. $\mathrm{He}$ said, "I think some of the negative stereotypes that come with being a young MexicanAmerican male, can sometimes hinder you, sometimes teachers can actually look at you and not think you are capable of much." With a family to support, he had realized the importance of college to his earnings potential. Isaac felt intellectually capable, though practically unprepared, for college work. For example, he said, "I didn't know about financial aid until my second semester there ... I didn't know any of that stuff just because nobody thought that I could make it in college."

Elena was a 28-year-old single mother of two small children. She identified herself as Mexican-American, and felt this heritage was important to carry forward to her children, whose father was White. She stated, "I want to [make] sure my son knows the language and doesn't lose that part ... you have Mexican blood, you should be proud of it." Elena never felt that teachers treated her differently because of her ethnicity, though she did talk about experiencing some discomfort outside of the classroom. "Sometimes during breaks it's kind of awkward, on both parts, like we just don't have anything in 
common ... if someone White is there, and they start talking about Yoga or something . . . does he think because I'm Mexican, that I don't know anything about it? It's just awkward at times."

Gina was a 20 -year-old single female, full time community college student. She could not recall ever being treated differently because of her ethnicity, which she identified as Latina. Asked for a more specific background, she said "I'm actually Mexican and Puerto Rican", which doesn't fit neatly into the standard categories, beyond Hispanic. Her goal was to transfer to a 4-year college, though she has not decided on a specific major.

Marta was a 25-year-old single female, full time community college student. Asked about her ethnicity, she responded, "I am Hispanic, or Latino. Mexican, and Salvadorian." Her spoken English was unaccented and rich in vocabulary, and she felt that she had never been treated differently because of her ethnicity.

$\underline{\text { Paola }}$ was a 19-year-old single woman in her second year at the community college. She identified herself as Mexican, and was the daughter of Mexican immigrants who operated a local grocery store. Paola didn't feel as though she had been treated differently in school, based on her ethnicity. As she said, "not everyone knows that I'm Mexican because I don't really look it, but I am." The high school and community where she grew up had a majority of Latino students, and Paola felt "a little bit more welcome" there than she did on the Costanza campus, which had a White majority of students. She was excited to have gotten an Android phone: "I email on it, I do Facebook." 
Magda, a 36-year-old married female, was the oldest participant. She identified herself as Mexican, and had three children, ages 15, 12, and 9. She had just returned to school, was thoughtful and respectful in her responses, and quick to take responsibility for the outcomes in her classes. She denied any consideration of ethnicity in her education, and said, "I don't think it benefits or affects me, I just don't think about it." Magda was comfortable with computer systems, "anything to do with an office system. I have a cell phone and sometimes text, but only to my kids when they text me and I need to text them back."

Hector was a 25-year-old single male, one semester away from earning a masters degree in electrical engineering. He planned to enroll in an MBA program, and had returned to the community college to take some of the prerequisites for a business degree. Hector had taken six prior online classes, and liked the efficiency of the format. $\mathrm{He}$ identified himself ethnically as Mexican, and didn't believe it has ever affected him. He said, "I don't perceive myself either ahead or below anybody else."

No evidence of deficits among participants.

While Costanza College administrators and instructors attributed exacerbation of the Latino-White achievement gap in online classes to Latino student deficits in technology, language, and motivation, there was little evidence of these deficits among study participants. Every participant expressed a high level of comfort with computers and the Internet, and all had been using computers since grade school or before. Gina did all of her schoolwork on the computer, using "Microsoft Word, Excel, PowerPoint, 
Photoshop, the Internet, email, web browser, Facebook." Helena was "always on the computer . . comfortable with Word, Excel, Access, the Internet, shopping, social networks." Marta had become active in Farmville, a computer simulation game currently popular on Facebook, saying "I've used a computer since I was very young, first grade." Gerardo got his first PC at age 7; Isaac in sixth grade.

Interviews were conducted in English, and were characterized by highly articulate exchanges, demonstrating a strong command of the language. Only Gerardo and Marta expressed the feeling that learning English as a second language had hurt them. Marta said, "I feel like I write better in Spanish. I would probably do better if I . . . could do [papers] in Spanish than in English." No writing samples were collected for the study, so it was not possible to assess participants' capabilities with written English.

Motivation was high among participants, who had chosen online classes because they wanted to further their education, despite personal, work, and family commitments that made it difficult to enroll in face-to-face classes. Isaac said, "I had to move my schedule around so that I have all online courses and have night classes and still work 85." "It works well with my schedule. I could check it whenever I have time," said Elena. Marta chose the online class "mainly because I have a baby. But I'm also working and I can't afford childcare. I work 21 hours a week." Miguel looked forward to eliminating the cost of an additional trip to the campus, saying "for me to come out here and back, it costs somewhere around \$3-\$5 depending on the car that I'm driving. To do that twice in a day is just asking so much from me personally." 
Participants were also not choosing online classes because they thought they would be easier than face-to-face classes. Expectations about the difficulty and time required for an online class, expressed in interviews before the semester was fully underway, were equivalent with the difficulty and time required for a face-to-face class, although participants anticipated differences. Hector, with the most prior experience in online classes, concluded, "they take a little bit more work usually, but I think what you get out of it is about the same." Helena, who also had previous experience with an online class, said, "It's harder in the sense that you have to be on top of yourself. You don't have a set class time with a teacher to tell you what your homework is. It's your responsibility to look it up and get it done with enough time." Paola, enrolled in her first online class, also anticipated a slightly more difficult experience: "I feel like it's going to be a little harder because I know if I have a question, I could just ask the teacher face-toface, and I know I can ask through email too, but I fell like it is not the same." Marta said, "I think it would probably take around the same amount of time, [but with] more homework assignments. Just less face-to-face time, so maybe in order for us to remember it or, I don't know, try to make up for it with more homework."

\section{Little evidence of equivalence.}

Other than the amount of effort required, participants did not consider online classes to be equivalent to face-to-face classes. Partway through the semester, almost every participant expressed concerns about the difficulties they were having with their online classes. Marta said, "I feel like I don't get to know the instructor as well as if I 
were in a classroom situation. I hardly know what he looks like. I don't really know what he sounds like, how he lectures or anything except for what is written." Gina had realized how much she prefers face-to-face classes, instead of online classes, reflecting on her online experience as "just a lot of work ... reading and trying to understand all the concepts. I definitely work better being in a classroom."

By the midpoint of the semester, of the four students, Miguel, Isaac, Gina, and Hector, who did not return for the final interview in the study, only Hector did not express misgivings about his online class. Isaac had clearly decided to drop all but one of his online classes by mid-semester. “At first I wasn't able to get any books, I couldn't afford them and I tried making copies at the library and I lost my baby sitting and it was nuts. I dropped all of them besides English, which I am just taking for credit." Isaac expressed a frustration, common across all participants, with the poor communication he experienced with one of his instructors:

I would submit things and I would feel like it was never enough. And then when you tried to communicate, you would get really small responses. I know he must be really busy but I think that was the only class ... that I didn't really have a relationship at all. It was a little bit of the timeliness and the depth of the responses [that made me feel this way]. He just seemed really busy. I can't judge anymore than that.

Miguel, who also did not return for the final interview, was frustrated by the middle of the semester. "I have zero relationship with my instructor," he said. When 
asked whether he felt this was about the instructor, or the online environment itself, he said,

I think it's both the environment and the teacher combined ... I think if there is going to be a person behind a classroom, grading and setting up the syllabus and all of that for the class, I think they should have more of a connection with their students, as opposed to setting it up and just letting them go do it. Right now, it's just to the point where assignments are just being graded, and there is very little feedback.

Pressed about how much of his frustration was with the instructor, Miguel said, "I've never met the guy. I don't know if he is a good teacher or not." Gina attributed her instructor's lack of responsiveness to the teaching workload, saying, "If I have had trouble, I've contacted her a couple of times but because of the fact that she has so many students, I'm assuming her other online classes, that she does, it's hard for her to get around to it." This absence of a relationship with the instructor was consistently cited by participants as an impediment to their success in the online class.

\section{Relationships most important.}

Mutually respectful relationships were the key determinant of whether participants categorized a prior class as good or bad. During the first interview, participants were asked to recall a particularly good class they had taken in the past, and then to describe that class. They were then asked to recall and describe a particularly bad 
class. In every example, of both a good class and bad class, and for every participant, the description started with the instructor.

Initially participants provided general praise for the instructor in the good class: "He was a really motivating teacher," said Helena; "It was the way he presented the stuff," said Gerardo; "Our teacher was just amazing," said Marta. When pressed for specifics, there was a consensus around the importance of student access. Hector said, "He was very available ... even through email, he would respond to you as soon as he could." Good instructors also knew their subject, and communicated that knowledge effectively. "He knew what he was talking about, he answered any question you needed. You would ask him a question and he would just tell you straight up how it was and what he thought about it," said Gerardo.

In good classes, participants didn't characterize the teacher as easy, but rather as earning their respect. "He was quick to correct me . . . I felt like he was someone that I could easily open up to, without being judged," said Gerardo. Isaac pointed out how some teachers would ask you a question because they thought you were not paying attention. In the good class, Isaac said, "He wasn't like that. He asked us what we thought; he asked us to participate, he was more like, if you want to participate then you can, but if not, you don't have to." Elena told a story about her teacher using her essay title as an example to the class, of what not to do:

I was like, oh my god, that's the title I wrote, and he would say that this was too simple, I'm not going to say names, but this is too simple, I want to see something 
different. I was so embarrassed and I was like, should I even approach him about this but he was very approachable and when I did, he said that he didn't mean to attack anybody, I just wanted to let you guys know to think about better titles and he didn't make me feel bad at all once I talked to him ... I respected him and he respected me.

Gina reinforced this idea of respect being mutual, stating "she would never blow you off."

Descriptions of bad classes also began with the instructor, and all except one of the participants had a powerful memory of at least one really bad instructor. Marta, the one exception, took personal responsibility for her bad classes, or, as she put it, "there are subjects that are harder for me to understand." Other than Marta, however, no one cited difficulty as a factor in their bad class. Instead, Isaac described his bad class this way: It was real easy. She just probably wanted to get it done. Maybe they just threw all the kids that were problematic at her . . . she bumped my grade up from an A to an A plus. She had us help her with some manual labor. She's like, I'm taking my classroom from here to here, so help us out here. In high school . . . you can bump up your grade if they think that you're a student that's just not going to make it."

In the same vein, Miguel said, about his high school biology class, "we got a photocopy out of a text book, and it had a picture or a diagram of whatever we were studying at the 
time and we were supposed to color it. Somehow I got a B, and I remember not doing work."

For some, the issue in the bad class was just getting information from the teacher. "There was usually a line of people waiting for him [after class]," said Hector. And Gerardo said, "You would ask a question and she would talk to you like an idiot for not knowing, and it kind of seemed like she hesitated, like she didn't know the answers." Elena said, "he would kind of confuse us ... and it was hard for him to explain to us why it was one solution and not the one that we showed. I felt like I didn't learn much." Gina echoed this perception from her own bad class, saying "he didn't really answer what I needed, so he just made it kind of difficult."

Lack of mutual respect was the common theme when participants discussed their bad instructors. Elena felt sorry for her instructor, but "would feel like I couldn't even ask him, he's just going to confuse me even more ... I tried not to disrespect him.” Helena lamented her instructor's inability to explain concepts in terms relevant to his students: Why do I need to think like him to know the answers? I shouldn't have to think like him to answer the correct answer, I should have to think about what information that I know, not what tricks is he going to use in the question. He was trying to give us information, not necessarily teaching it. There's a difference.

There really is."

Gerardo described the arrogance of his bad instructor, saying, "She was opinionated and biased and conservative and it was like her way or the highway." Gina put it this way: "It 
was pretty much, if you failed, then you failed. It's like, you have to be on top of it like that, instead of him trying to help you."

Relationships lacking in online classes.

In contrast to the participants' characterizations of strong, respectful relationships they had experienced with instructors in their good class, described earlier, it was striking how negative their comments were about their relationship with instructors in their online class. "We don't really have a relationship," said Gerardo. "It's like, do your work, and so I do my work, and that is about it." Helena found the relationship with her instructor to be missing any personal connection: "It's very about coursework and that is that. She doesn't care about what is going on in my life."

When asked if she had a relationship with her instructor, Marta replied, "No, not really. I wouldn't say I do.” Asked if that mattered to her performance in the class, she said, "I do all the assignments but I don't feel like I am going to go beyond just the basic requirements." Magda allowed that, "maybe for other people, it would work better, because they don't like to interact with other people or their teachers, but I am probably different." Paola tried to put herself in the instructor's place, saying that "if I was the teacher, I don't think I would want to talk to everyone, every day, but it would be nicer if they could check in and see how you're doing, and tell you how you are doing, too." She concluded that, while she received emails from the instructor, announcing upcoming assignments or grades on quizzes, as far as having a relationship with him, "No, no real relationship." 
Only two participants were not negative about their relationship with their online instructor. The first of these, Elena, had established a relationship, through a prior online class, with her current online instructor. When she ran up against a deadline on an assignment, encountering technical problems that precluded her from getting it submitted on time, she was able to leverage that relationship. As she related the story,

[the system] locked me out at midnight which was the time she told us that it would lock us out. And I just let her know and I emailed it to her and told her and she said just go ahead and do it. We have a relationship. She understands, she's very understanding ... We have a good relationship, I think, [even though] we haven't met in person.

The second participant who described the relationship with their instructor in more neutral terms was Isaac. Referring to the English teacher in his one remaining online class, Isaac said, "we email back and forth, and just when we need to. I think she has been sick for a while, but it's not bad, from an online instructor."

\section{Participant outcomes.}

The final interview was conducted during or immediately after finals week, in December 2010. Of the six participants who returned for this last interview, only two seemed satisfied with their online experience. Gerardo said, "I like it." He got a C in the class, and remarked that, "it took a lot of time. The material was very difficult." When pressed on why he thought it was a good class, he responded, "It's because the book was good and I didn't have a lot of questions, so the instructor wasn't needed as much." 
Elena, the second participant with a positive online experience, was also the one person who felt that she had a good relationship with her instructor. The key aspect she appreciated about the online format was the flexibility she was granted on due dates: "I would set myself my own due date, on Friday, I'm going to get it done, but it would take longer sometimes."

Helena's experience with due dates was quite different, since she was dropped from her class for missing a deadline. As she tells it, "one of those things, like, I did it, didn't turn it in, then I sat up Saturday morning and was like, oh my god, I can't believe I didn't do that!" When asked to confirm that she was dropped from the class for missing one due date by one day, Helena said, "Oh, she's very hard deadline, no excuses, like unless, unless you come in with a death certificate or something legally binding, no exceptions."

Marta and Paola were in the same class, and both would have preferred to get more feedback on their progress through the semester. Marta completed the class, but noted that it "took probably a little more time than I though it was going to take ... more reading and less skimming." Paola, who was interviewed after finals were over, said "It worked out good. Well, not bad." When asked how she had done in the class, she said that she really didn't know yet, that some of her assignment grades had not been posted yet. Then she admitted, "I could have done better, though ... I just really like in-class classes more than online." 
Magda did not do as well in her online class as she had hoped she would. "I passed with a $\mathrm{C}$, and I did work hard to get that $\mathrm{C}$. I probably needed more communication with the teacher." Magda remarked that she had emailed her instructor "every now and then, but not much." When asked how long it took to get a reply, she said, "Um, very fast. Two or three days." Asked to confirm that she considered two or three days to be fast, Magda replied, "It was alright. It was OK . . .It's my fault, I think, I mean the way I am, probably that I need to be physically in a class environment."

\section{Summary of Findings}

The quantitative portion of this study revealed a systemic inequity in student outcomes enrolled in online classes, with a generally greater penalty incurred by Latino students than by White students. Because of this, online classes exacerbate the LatinoWhite achievement gap in California community colleges. The qualitative portion of the study began a process of understanding how Latino student experiences might help explain the poor outcomes in online classes.

The interviews revealed a group of Latino students who were very capable with technology, including personal computers, general productivity computer applications, and the Internet. Students' expectations about their online classes seemed to be realistic, with none of the students believing beforehand that the online class would be easier or require less time than the face-to-face class.

Participants were unanimous in identifying the instructor as the primary determinant of whether a class was good or bad. In fact, when asked to describe a good or 
bad class from their past, the descriptions invariably began with the instructor. Additional prompting was required to learn what it was about the instructor that made the class so good, or so bad. Good classes were characterized by instructors who created strong, mutually respectful relationships between themselves and their students, while bad classes were remarkable in the absence of these sorts of relationships.

Participants' experience of their online classes during the study semester was generally not positive. Of the two students who expressed neutral or positive reactions to their classes, one was grateful that a high quality textbook meant the instructor was not needed as much, while the second had developed a positive relationship with their instructor during a previous semester. In addition, while flexibility of timing was one of the most important reasons cited for enrolling in an online class, some participants experienced a lack of flexibility in the implementation of their class, especially related to assignment due dates. However, the main source of dissatisfaction with their online class was the lack of a mutually respectful, positive relationship with the instructor. 


\section{Chapter Five: Discussion and Implications}

The current study had its genesis in the small-scale evaluation of student outcomes in online and face-to-face sections of courses at Costanza College, discussed in Chapter 1. In that evaluation, students in online sections did not do as well as in face-toface versions of the same courses. In addition, because the online penalty was larger for Latino students than for White students, the Latino-White achievement gap was exacerbated in online sections. These results seemed to contradict the consensus of prior research, that online instruction is essentially neither better nor worse than face-to-face instruction. Further, they pointed to an underlying equity issue that had not previously been explored. The institutional response to this equity issue, from Costanza College instructors and administrators, was to ascribe poor outcomes to deficits of technology, language, and motivation among Latino students. The current study rejected this deficit model, and instead sought to give voice to Latino students' experiences of their online classes.

The research question for the current study was: How does enrollment in online classes impact academic success for California Latino community college students? An explanatory mixed methods approach was used, employing a quantitative analysis of statewide student outcomes, followed by qualitative research with ten Latino/a online students. The quantitative section evaluated differences in outcome across student attributes of ethnicity, gender, and goal, and across course attributes of transfer, vocational, and basic skills status. The qualitative section focused on the importance of 
mutually respectful relationships to teaching and learning within the Latino community, expressed through the Mexican sociocultural construct of educación.

\section{Overall Outcome in Online Classes}

Between May 2005 and July 2009, Latino and White students, presented with a choice of online or face-to-face sections of their California community college course, experienced a minor penalty for enrolling in the online sections. The average grade earned in online sections, of 1.92 on a 4-point scale, was just 0.06 standard deviations lower $(\mathrm{p}<.001)$ than the average grade of 2.02 , earned in the face-to-face sections. This finding is consistent with the consensus in the literature (Bernard et al., 2004; Zhao et al., 2005; Means et al., 2009) that online classes are neither better nor worse than face-to-face classes.

Composition of Online Classes Masks Online Penalty

Latino students in California, presented with a choice between online and face-toface sections of the same course, are about $30 \%$ less likely to enroll in the online section than are White students. Accordingly, Latino students are relatively underrepresented in online classes, while being overrepresented in face-to-face classes. This finding is consistent with the one other comprehensive study that discussed ethnicity (Jaggars \& $\mathrm{Xu}, 2010$ ), which reported that Black and Hispanic students were less likely to take an online course than were White students. Combining this skew in the ethnic composition of the different class formats, with the well-documented achievement gap between Latino 
and White students, has the effect of masking the online penalty for Latino and White students alike.

This effect was illustrated in the contrast between Table 5 and Table 6, in Chapter 4. In Table 5, the GPA for the 67,474 students who had a goal to update job skills was 2.33 in the online sections, slightly better $(\mathrm{p}<.05)$ than the 2.30 GPA earned by students with the same goal, enrolled in face-to-face sections of the same courses. However, disaggregation of these same data by ethnicity and gender in Table 6 revealed a minor online penalty of 0.04 standard deviations for White women $(p<.01)$ and a moderate online penalty of 0.14 standard deviations for Latinas $(p<.001)$. These differences, while relatively small in the absolute, exacerbated the Latino-White achievement gap, from 0.24 standard deviations $(\mathrm{p}<.001)$ in face-to-face classes to 0.34 standard deviations $(\mathrm{p}<.001)$ in online classes, a substantial and troubling outcome. A similar effect was observed when the data were disaggregated by ethnicity and gender for all goals combined, in Table 7. In that case, the Latino-White achievement gap of 0.25 standard deviations $(\mathrm{p}<.001)$ in face-to-face classes was exacerbated to 0.36 standard deviations $(p<.001)$ when students enrolled in online classes.

Only two areas were found to have no meaningful equity issues arising from the online penalty. First, the UC success rate, defined as earning a B or better in the class, was not different in any meaningful way between online and face-to-face classes for either ethnicity, although there was a large, 12 to 13 percentage point achievement gap between the Latino and White student UC success rates overall. The second area where 
no online penalty was measured was among underprepared students, enrolled in basic skills courses. In that case, there were no statistically different outcomes based on ethnicity, gender, or the format of the class. Unfortunately, the average grade earned was well below the passing level for every combination of ethnicity and gender, in both faceto-face and online sections, for basic skills students. These uniformly poor results shed no light on the research question of the current study.

Online Penalty Varies by Ethnicity, Gender, and Goal

In every other combination, a consistent pattern emerged in the relationship between the magnitude of the online penalty and the ethnicity and gender of the students. White males experienced the smallest online penalty, never rising to a meaningful effect size. For White males, the online penalty ranged from 0.03 standard deviations $(\mathrm{p}<.05)$ for White males with a vocational goal, enrolled in occupational courses, to 0.13 standard deviations $(\mathrm{p}<.001)$ for White males with a transfer goal, enrolled in transfer courses. In the aggregate, across all goals and courses, White males suffered a minor online penalty of just 0.07 standard deviations $(\mathrm{p}<.001)$.

Latina students consistently paid the highest penalty for enrolling in online courses. Across all goals and courses, Latinas experienced an online penalty over twice as large, at 0.16 standard deviations $(\mathrm{p}<.001)$, as the online penalty experienced by White males across all goals and courses. When broken out by goal and course, the online penalty for Latinas ranged from 0.14 standard deviations $(\mathrm{p}<.001)$ for Latinas 
with a vocational goal enrolled in occupational classes, to 0.21 standard deviations $(\mathrm{p}<.001)$ for Latinas with a transfer goal enrolled in transfer classes.

Across all goals and courses, White females and Latinos both experienced an online penalty, at 0.10 standard deviations $(\mathrm{p}<.001)$, that was smaller than the online penalty experienced by Latinas, and larger than the online penalty experienced by White males. Among students with a transfer goal enrolled in transfer courses, the online penalty for White females and Latinos, at $0.16(\mathrm{p}<.001)$ and $.17(\mathrm{p}<.001)$ standard deviations respectively, also fell between those experienced by Latinas and White males. White females with a vocational goal enrolled in occupational courses also experienced an online penalty, at 0.06 standard deviations $(\mathrm{p}<.001)$ that fell between those experienced by Latinas and White males. Most intriguing, Latinos with a vocational goal enrolled in occupational courses experienced no statistically significant online penalty at all.

Although the relative size of the online penalty was consistently largest for Latinas and smallest for White males, there was also a relationship, illustrated in Figure 2, found between the academic rigor of the students' goal and selected course, and the magnitude of the online penalty. Students with a transfer goal enrolled in transfer courses experienced the largest online penalty. This penalty was largest for Latinas, at 0.21 standard deviations $(\mathrm{p}<.001)$, followed in order by White females, at 0.17 standard deviations ( $\mathrm{p}<.001)$, Latinos, at 0.16 standard deviations $(\mathrm{p}<.001)$, and White males, at 


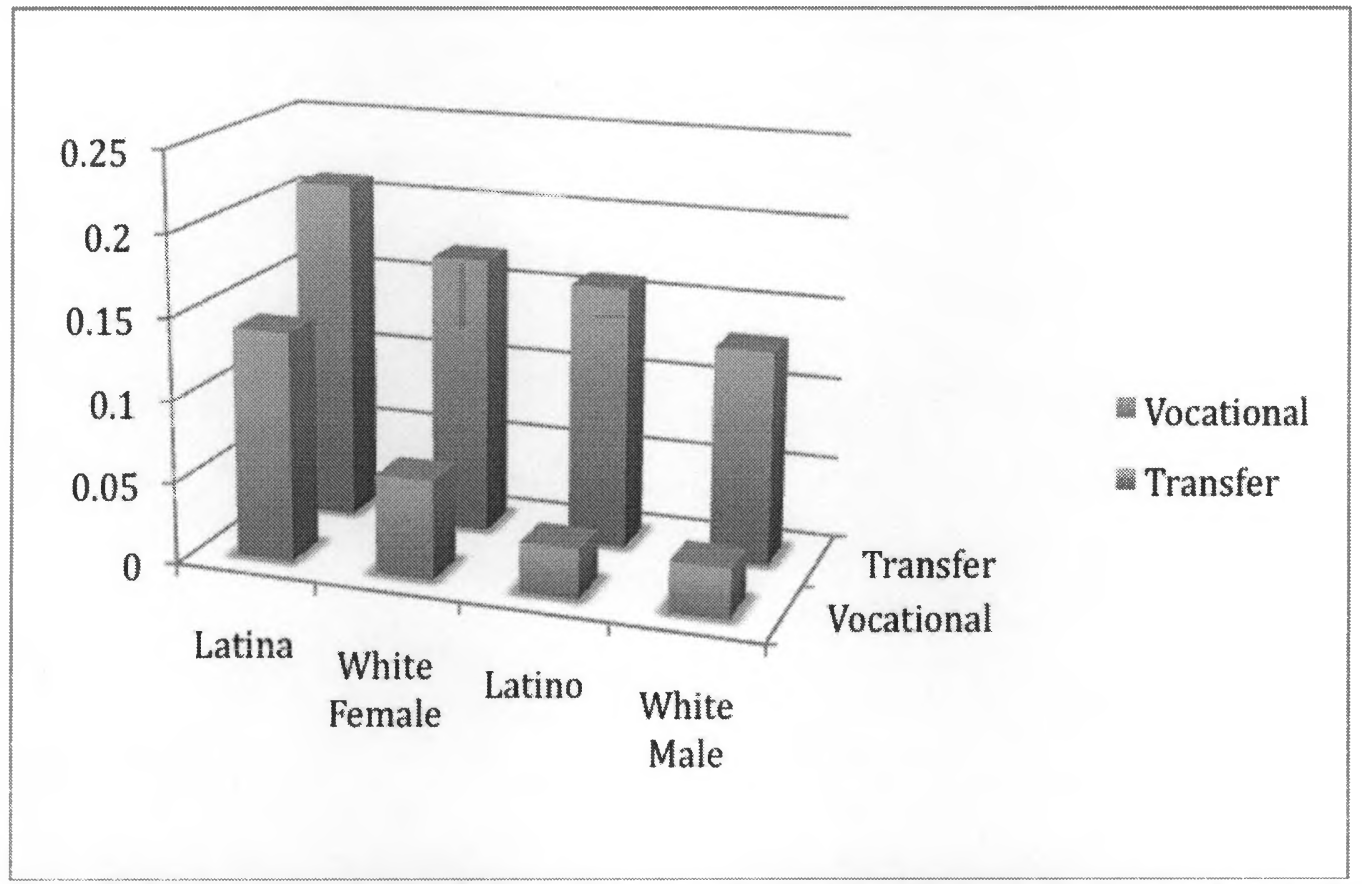

Note: Online penalty of .03 SD for Latino vocational students was not statistically significant.

Figure 2: Online penalty vs. face-to-face, in standard deviations, by student attribute and goal

0.13 standard deviations $(\mathrm{p}<.001)$. For every combination of ethnicity and gender, the magnitude of the online penalty was lower for students with a vocational goal enrolled in occupational courses, and essentially disappeared for underprepared students enrolled in basic skills courses.

\section{Latino Student Deficits Rejected}

The qualitative portion of this study did not support the idea that Latino student performance in online classes is worse because of deficits in language, technology, and motivation. Their responses to questions were articulate, and their command of spoken 
English was essentially flawless, though written English literacy was not assessed. The interviewed students also displayed great facility with technology, maintaining contact with the researcher throughout the semester using email, and coordinating scheduling of interviews using an appropriate combination of email, text messaging, and telephone contact. All study participants had experience using technology to maintain relationships, through social networking sites like Facebook, and using text messaging and email. At the beginning of the semester, participant motivation was clearly high enough to result in enrollment in their selected class, in spite of significant challenges of scheduling, family, and work obligations. As the semester wore on, however, poor or absent relationships with instructors eroded this initial motivation.

\section{Missing Instructor Relationship in Online Classes}

In every instance, participants in the qualitative portion of this study credited a particularly good instructor as the primary determinant of a positive outcome in previous classes. When pressed to describe what it was about the instructor that stood out, all participants cited the strong, mutually respectful relationship they had developed with that instructor. Conversely, negative outcomes in previous classes were attributed to bad instructors, characterized by bad relationships. These findings are entirely consistent with the Latino sociocultural perspective reviewed in Chapter 2, as articulated by Valenzuela (1999), Solorzano (2005), and Duncan-Andrade (2008).

Only one of the ten participants in the qualitative portion of this study experienced a good relationship with their online instructor during the study semester, 
and that one student, Elena, had a prior relationship with her instructor, developed in a previous online class. While this exception demonstrates that good relationships between students and instructors are possible in the online environment, the fact that it is a sole exception points to a finding that such relationships are, at best, uncommon. Participants' relationships with their online instructors during the study semester are best summed up by Miguel's response, when asked to characterize his relationship with his online instructor: "What relationship?"

Responsibility for this failure to develop and maintain positive instructor-student relationships belongs with the online instructors. Student participants had developed and maintained relationships online with people other than their online instructors, and study participants were likely more accustomed to communicating using technology than were their instructors. Elena's experience showed that it is possible for an instructor to develop and maintain a positive relationship with an online student. Having a student wait two or three days for a response to a question may be equivalent to a face-to-face class that meets in person twice per week, but is completely inappropriate for an online class, where relationships rely entirely on responsive communication, mediated by technology.

\section{Study Limitations}

The quantitative portion of this study was limited by (a) a focus on Latino and White students; (b) use of grade earned as the measure of outcome; and (c) lack of access to instructor and course features. In the California community college system, the achievement gap generally refers to the disparity in outcomes between White and Asian 
students on one side, and Latino and African American students on the other side. Because the study was limited to Latino and White students, the full impact of online instruction on the achievement gap was not assessed.

Variation in grading was evidenced in the relatively large standard deviations, typically in excess of 1.5 grade points, calculated during this study. Conversion to effect sizes for analysis of differences corrected for this variation, but it may be possible that systemic factors related to grading are at play. Grading policies and rigor almost certainly vary among campuses, departments, and individual instructors. Use of over four million student records, across all campuses, minimized the risk of this sort of bias. However, if occupational programs were found to give higher grades in general, for the same level of student achievement, than transfer programs, that could easily account for the differences in student outcomes between these two areas.

Information about the instructors and methodology was not included in the data used for the quantitative portion of the study. If the findings from the qualitative portion of the study, that positive outcomes for Latino/a students arose from mutually respectful relationships between student and teacher, then instructors creating such relationships could be expected to have better student outcomes than would instructors who did not create such relationships. Further, if teacher quality is, as some would argue, the single most influential variable driving student outcomes, then differences in the quality of instruction between online and face-to-face classes could be the most important factor 
producing the results in this study. Without data about instructor quality, there is no way to test this relationship.

The qualitative portion of this study was limited by self-selection of study participants from a single school, and by the small sample size, reduced from 10 to 6 participants by the end of the semester. Students were recruited for the study using email, and it is accordingly likely that those responding to the solicitation were more comfortable communicating via email, and by extension, technology in general. If true, this effect could have skewed the qualitative finding that online Latino/a students were comfortable using a range of technologies. In addition, students interested in participating in a study for a doctoral dissertation may have been more academically advanced, with more highly developed communication skills, than students who did not choose to participate in the study.

\section{Implications}

Despite the limitations described above, this study has exposed a clear, systemic equity issue related to the California community college system's implementation of online classes in general. In most cases, students pay a penalty for enrolling in online classes, and this penalty is larger for Latino students than for White students, thus exacerbating the Latino-White achievement gap. Attribution of this effect to Latino student deficits is not borne out in the stories of the students that participated in this study. As accountability for student outcomes continues to become more prevalent in 
California's community colleges, schools will need to be sure their assessments include a focus on equity issues around ethnicity and gender.

From a policy perspective, use of equivalency as the criteria for adoption of technology has been ineffective. Equivalence of student learning outcomes between different approaches is a valid goal. However, the absence of rigorous measurement of these outcomes has left colleges with activity measures as the only way to evaluate equivalency between online and face-to-face classes. Instructors enforce hard deadlines in their online classes, equivalent to their face-to-face classes, in spite of the fact that online students cite flexibility of the time commitment and unpredictable work and family schedules as key reasons for choosing the online format. One online instructor implemented a policy of responding to email from students within three days, equivalent to the frequency of communication with a face-to-face student in a twice-weekly class, but frustrating and unacceptable to an online student. Online classes are scheduled to fit within standard semesters, with an equivalent expectation of the number of hours per week students will spend on the class, negating the inherent ability of online technology to adapt to different paces of progress among students.

Policy regarding evaluation of online instructors is also implicated in this study. The stories told by study participants, about their online classes, lead to the troubling but unavoidable conclusion that, for these students, these particular instructors are not effective in the online environment. The broad, systemic inequities in online outcomes revealed in the quantitative portion of the study, point to a potential concern about the 
overall quality of online instruction. At Costanza College, instructors who want to teach an online class can do so with no special training or preparation. To make this work, online technology has to be adapted to deliver the existing content, in ways consistent with the instructor's face-to-face practice, rather than adapting the instructor's teaching to the technology of the online environment.

\section{Recommendations}

This study produced findings that merit two main courses of action among instructors and administrators within the California community college system. First, online programs at colleges should develop reporting systems that measure and compare online and face-to-face student outcomes across the dimensions of ethnicity and gender. These reports can then be used, in a community of practice among online instructors, to understand the equity issues arising from their online classes, and to experiment and report on creative solutions that address these issues. Second, online instructors should be encouraged, or perhaps required, to complete a certification program before being allowed to teach an online class. The community college system has recognized the need for training instructors about online teaching and learning, and has created a voluntary certification program, available to any aspiring online instructor, and implemented through the system office.

This study also raised a number of questions that merit further research. Broadly, these questions fall into two areas: (a) Student characteristics, and (b) course and instructor quality. 
It will be important to extend the quantitative and qualitative analyses to include other subordinated student populations. African American community college students in particular may be subject to similar equity issues around online instruction as were seen with Latino students. Also, inclusion of data related to student socioeconomic status would enable a multivariate approach, to determine the extent to which socioeconomic class influences online student outcomes.

Gender influences on online student outcomes also warrant additional study. In this study, it was poorer outcomes for Latinas that resulted in the most dramatic exacerbation of the Latino-White achievement gap. Gender-based sociocultural influences were not explored, but it is likely that young women navigating Latino cultural constructs face unique challenges in the conflict between career-focused college enrollment and more traditional female roles as the primary family caregiver.

Additional research on the impact of literacy should be done. This study did not assess written English competency of participants, nor was there any evaluation of technology literacy in the academic environment. Quantitative data are available to link students' English course enrollment history with outcomes in online classes, and analysis of the relationship between enrollment in developmental English classes and success in online classes could provide valuable guidance to online programs. There may also be a level of technology literacy, required for success in online classes, that goes beyond the texting, social networking, productivity software, and game system proficiency demonstrated by these study participants. Exploration of online instructional 
environments, using the theoretical framework of discourses, might extend our understanding of the skills required for online student success.

Finally, there is also a need to assess the quality of instruction in online classes, to connect specific approaches and implementations to improved student outcomes, particularly among subordinated students, and to evangelize these successful approaches throughout the online education community. Quantitative data are available that link specific instructors to student outcomes, and a multivariate analytical approach that included instructor effects could help calibrate the relative importance of instructor quality. The fact that the online penalty was larger in transfer courses than in vocational courses suggests that there is a great deal left to learn about appropriate use of technology for various curricula. It may be that vocational courses, focused on specific technical skills for career development, are less reliant on relational approaches to teaching and learning. Practitioners and researchers need to broadly share their developing knowledge about effective use of online instruction and its impact on the achievement gap, as the technology continues to move into mainstream post-secondary educational practice. Conclusion

Before I began teaching in the California community college system, I spent 20 years at various technology companies in the private sector. Mostly, we tried to figure out ways to use new technology to solve problems, to do something better than it could previously be done. I believe that the Internet and Web 2.0 represent a collection of technologies uniquely suited to dealing with social issues, including the achievement gap. 
It has been extraordinarily discouraging to see how our institutions have instead deployed online instruction in ways that make things worse, not better, for our most subordinated students. As studies like this one, and others that follow in the same vein, shine a light on equity issues around online instruction, I am hopeful that creative and concerned online instructors and administrators become motivated to use the technology to solve, rather than exacerbate, the achievement gap. 


\section{References}

Allen, I. E., \& Seaman, J. (2007). Online nation: Five years of growth in online learning. Needham, MA: Sloan-C.

Azzam, A. M. (2006). Digital opportunity. Educational Leadership, 89-92.

Bartolomé, L. (2009). Beyond the methods fetish: Toward a humanizing pedagogy. In A. Darder, M. P. Baltodano, \& R. D. Torres (Eds.), The Critical Pedagogy Reader (Second ed., pp. 338-355). New York: Routledge.

Benson, A. D., Johnson, S. D., Taylor, G. D., Treat, T., Shinkareva, O. N., \& Duncan, J. (2005). Achievement in online and campus-based career and technical education (CTE) courses. Community College Journal of Research and Practice, 29, 369-394.

Bernard, R. M., Abrami, P. C., Lou, Y., Borokhovski, E., Wade, A., Wozney, L. et al. (2004). How does distance education compare with classroom instruction? A metaanalysis of the empirical literature. Review of Educational Research, 74(3), $379-439$.

Bertalanffy, L. v. (1968). General system theory. New York: George Braziller.

Bourdieu, P. (1990). The logic of practice (R. Nice, Trans.). Cambridge: Policy Press.

Bower, B. L., \& Hardy, K. P. (2004). From correspondence to cyberspace: Changes and challenges in distance education. New Directions for Community Colleges, 2004(128), 5-12. 
Cammarota, J. (2004). The gendered and racialized pathways of Latina and Latino youth: Different struggles, different resistances in the urban context. Anthropology \& Education Quarterly, 35(1), 53-74.

Chavez, L., Medina, O., \& Arrdondo, G. (2007). Is the bay area preparing Latino high school graduates for college? A statistical portrait of college preparation in the San Francisco bay area. Institute for the Study of Social Change, University of California, Berkeley.

Christensen, C. M. (2008). Disrupting class: How disruptive innovation will change the way the world learns. New York: McGraw-Hill.

Cohen, J. (1992). A power primer. Psychological bulletin, 112(1), 155-159.

Delpit, L. (1995). Other people's children: Cultural conflict in the classroom. New York: The New Press.

Duffy, T. M. (2004). Theory and practice in distance education. In T. M. Duffy \& J. R. Kirkley (Eds.), Learner-centered theory and practice in distance education: Cases from higher education (pp. 17-48 ). Mahwah, NJ: Lawrence Erlbaum Associates, Inc.

Duncan-Andrade, J., \& Morrell, E. (2008). The art of critical pedagogy. New York: Peter Lang.

Elmore, R. F. (2004). School reform from the inside out. Cambridge, MA: Harvard Education Press. 
Felix, U. (2001). A multivariate analysis of students' experience of web based learning. Australian Journal of Education Technology, 17(1), 21-36.

Freire, P. (1970). Pedagogy of the oppressed. New York: Continuum.

Gee, J. P. (1989). What is literacy? Journal of Education, 171(1), 5-17.

Glass, G. V. (1976). Primary, secondary, and meta-analysis of research. Educational Researcher, 5(10), 3-8.

Hamilton, D. (1990). Learning about education: An unfinished curriculum. Philadelphia: Open University Press.

Hannay, M., \& Newvine, T. (2006). Perceptions of distance learning: A comparison of online and traditional learning. Journal of Online Learning and Teaching, $2(1), 1-11$.

Hayward, C., Cassada, J., Cordoba-Velasquez, Fillman, R. (2008). Cabrillo College factbook. retrieved on April 23, 2009 from www.cabrillo.edu/pro/factbook/.

HighTechHigh. (2008). A snapshot for 2008. Retrieved December 5, 2008, http://www.hightechhigh.org/about/.

Horn, L. (2009). On track to complete? A taxonomy of beginning community college students and their outcomes 3 years after enrolling: 2003-04 through 2006 (NCES 2009-152). Washington, DC: National Center for Education Statistics, Institute of Education Sciences, U.S. Department of Education.

Hunter, J. E. (2004). Methods of meta-analysis: Correcting error and bias in research findings. Thousand Oaks, Calif.: Sage Publications, Inc. 
Jaggars, S. S., \& Bailey, T. (2010). Effectiveness of fully online courses for college students: Response to a Department of Education meta-analysis. New York: Community College Research Center, Teachers College, Columbia University. Jaggars, S. S., \& Xu, D. (2010). Online learning in the Virginia community college system. New York: Community College Research Center, Teachers College, Columbia University.

Jones, S., Johnson-Yale, C., Millermaier, S., \& Perez, F. S. (2009). U.S. college students' Internet use: Race, gender and digital divides. Journal of Computer-Mediated Communication, 14(2), 244-264.

Keegan, D. (1990). Foundations of distance education (2nd ed.). New York: Routledge. Kennedy, D., Eizenberg, N., \& Kennedy, G. (2000). An evaluation of the use of multiple perspectives in the design of computer facilitated learning. Australian Journal of Educational technologies, 16(1), 13-25.

KewalRamani, A., Gilbertson, L., Fox, M. A., \& Provasnik, S. (2007). Status and trends in the education of racial and ethnic minorities (NCES 2007-039). Washington, DC: National Center for Education Statistics, Institute of Education Sciences, U.S. Department of Education.

Lapsley, R., Kulik, B., Moody, R., \& Arbaugh, J. B. (2008). Is identical really identical? An investigation of equivalency theory and online learning. Journal of Educators Online, 5(1), 1-19. 
Larreamedny-Joerns, J., \& Leinhardt, G. (2006). Going the distance with online education. Review of Educational Research, 76(4), 567-605.

Lim, D. H., Morris, M. L., \& Yoon, S.-W. (2006). Combined effect of instructional and learner variables on course outcomes within an online learning environment. Journal of Interactive Online Learning, 5(3), 255-269.

Mars, M. M., \& Ginter, M. B. (2007). Connecting organizational environments with the instructional technology practices of community college faculty. Community College Review, 34(4), 324-343.

Matusov, E., \& Hayes, R. (2000). Sociocultural critique of Piaget and Vygotsky. New Ideas in Psychology, 18(2-3), 215-239.

Means, B., Toyama, Y., Murphy, R., Bakia, M., \& Jones, K. (2009). Evaluation of evidence-based practices in online learning: A meta-analysis and review of online learning studies. Washington, DC: Center for Technology in Learning, U.S. Department of Education.

Millard, D. E., \& Ross, M. (2006). Web 2.0: hypertext by any other name? Paper presented at the Proceedings of the seventeenth conference on Hypertext and hypermedia.

Muilenburg, L. Y., \& Berge, Z. L. (2005). Student barriers to online learning: A factor analytic study. Distance Education, 26(1), 29-48. 
Mullen, G. E., \& Tallent-Runnels, M. K. (2006). Student outcomes and perceptions of instructors' demands and support in online and traditional classrooms. Internet and Higher Education, 9, 257-266.

Nather, K. (2007). Distance education report, fiscal years 1995-96 through 2005-06. Sacramento, CA: California Community Colleges System Office, Academic Affairs Division.

Navarro, P., \& Shoemaker, J. (2000). Performance and perceptions of distance learners in cyberspace. American Journal of Distance Education, 14(2), 15-36.

O'Reilly, T. (2005). What is Web 2.0: Design patterns and business models for the next generation of software. Retrieved December 4, 2009, http://oreilly.com/web2/archive/what-is-web-20.html.

Rendón, L. I. (2002). Community college Puente: A vaidating model of education. Educational Policy, 16(4), 642-667.

Rovai, A. P., \& Barnum, K. T. (2003). On-line course effectiveness: An analysis of student interactions and perceptions of learning. Journal of Distance Education, 18(1), 57-73.

Rovai, A. P., Gallien Jr., L. B., \& Wighting, M. J. (2005). Cultural and interpersonal factors affecting African American academic performance in higher education. The Journal of Negro Education, 74(4), 359-370. 
Rovai, A. P., \& Ponton, M. K. (2005). An examination of sense of classroom community and learning among African American and Caucasian graduate students. Journal of Asynchronous Learning Networks, 9(3), 77-92.

Rovai, A. P., \& Wighting, M. J. (2005). Feelings of alienation and community among higher education students in a virtual classroom. Internet and Higher Education, $8,97-110$.

Sengupta, R., \& Jepsen, C. (2006). California counts: California's community college students (8(2)). San Francisco: Public Policy Institute of California.

Shulock, N., \& Moore, C. (2007). Rules of the game: How state policy creates barriers to degree completion and impedes student success in the California community colleges. Sacramento, CA: California State University Sacramento, Institute for Higher Education Leadership \& Policy.

Simonson, M. (1999). Equivalency theory and distance education. TechTrends, $43(5), 5-8$.

So, H.-J., \& Brush, T. A. (2008). Student perceptions of collaborative learning, social presence, and satisfaction in a blended learning environment: Relationships and critical factors. Computers \& Education, 51, 318-336.

Solorzano, D., \& Delgado-Bernal, D. (2001). Examining transformational resistance through a critical race and Latcrit theory framework. Urban Education, $36: 3,308-342$. 
Solorzano, D. G., Villalpando, O., \& Oseguera, L. (2005). Educational inequities and Latina/o undergraduate students in the United States: A critical race analysis of their educational progress. Journal of Hispanic Higher Education, 4(3), 272-294.

Sumner, J. (2000). Serving the system: a critical history of distance education. Open Learning, 15(3), 267-285.

Szep, J. (2008). Technology reshapes America's classrooms. Reuters.

Trotter, A. (2008). Online options for 'credit recovery' widen. Education Week, $27(38), 1-4$.

Valenzuela, A. (1999). Subtractive Schooling. Albany: State University of New York Press.

von Lehmen, G., Zemsky, R., Kamentz, A., Bauerlein, M., Swan, K., \& Ehrenberg, R. (2010). College degrees without going to class. Room for Debate http://roomfordebate.blogs.nytimes.com/2010/03/03/college-degrees-withoutgoing-to-class/.

Vygotsky, L. S. (1978). Mind in society: The development of higher psychological processes. Boston: Harvard University Press.

Warschauer, M., Knobel, M., \& Stone, L. (2004). Technology and equity in schooling: Deconstructing the digital divide. Educational Policy, 18(4), 562-588.

Weick, K. E. (1976). Educational organizations as loosely coupled systems. Administrative Science Quarterly, 1(1), 1-19. 
Woodruff, D., \& Perry, P. (2008). Focus on results: Accountability reporting for the community colleges. Sacramento: California Community Colleges System Office.

Woods, R., Baker, J. D., \& Hopper, D. (2004). Hybrid structures: Faculty use and perception of web-based courseware as a supplement to face-to-face instruction. The Internet and Higher Education, 7(4), 281-297.

Zhao, Y., Lei, J., Yan, B., Lai, C., \& Tan, H. S. (2005). What makes the difference? A practical analysis of research on the effectiveness of distance education. The Teachers College Record, 107(8), 1836-1884. 
Appendix A

\section{Qualitative Interview Protocol}

Three open-ended interviews were conducted with each participant, including those who dropped their online course prior to the end of the semester. Interview 1 was scheduled during the first two weeks of the Fall 2010 semester, interview 2 around the eighth week of the semester, and interview 3 at the end of the semester. Interviews were conducted in the researcher's private office on the Costanza College campus, and were digitally recorded on a laptop computer, then transcribed verbatim by the researcher, with personally identifiable information masked. Once transcribed, the audio files were erased.

\section{Interview 1 Questions:}

Q1: What kinds of technology are you most comfortable with? (Follow up prompts for video games, cell phone and texting, online activities including email, social networking, blogging, shopping, school research, and previous online classes)

Q2: What are all the reasons that you chose to register for an online version this semester, instead of the classroom section of the same class? (Prompt for all reasons)

Q3: Do you think the online class will be harder, easier, or about the same as the classroom section? Is there any part of it that you're worried about? (Follow up prompts for time commitment, homework required, assignments required, flexibility, interactions with peers and instructor)

Q4: Think for a moment about a class you've taken in the past, that was really good. One where you learned a lot. Got it? OK, now tell me about that class. What was it that made it such a good class? (Follow up prompts for characterization of relationships with instructors and peers)

Q5: Now let's try it for a really bad class. Think of a class you took in the past, that was really bad. Tell me about that one, what was it that made it so bad. (Follow up prompts for characterization of relationships with instructors and peers) 
Interview 2 Questions:

Q1: How is the online class working out for you? (Prompt to tell more)

Q2: In our first conversation, you told me that a good class was [paraphrase Interview 1, Q4 response], and a bad class was [paraphrase Interview 1, Q5 response]. How does this class fit so far, along those lines? Good or bad? (Follow up prompt to explore online interactions with peers and instructor)

Q3: [IF RESPONDENT HAS DROPPED THE CLASS] Why did you withdraw from your online class? (Prompt for all reasons)

\section{Interview 3 Questions:}

Q1: How did the online class work out for you? (Prompt to tell more, grade, satisfaction, time commitment, difficulty)

Q2: In our first conversation, you told me that a good class was [paraphrase Interview 1, Q4 response], and a bad class was [paraphrase Interview 1, Q5 response]. Overall, how was this class? Good or bad? (Follow up prompt to explore online interactions with peers and instructor)

Q3: [IF RESPONDENT HAS DROPPED THE CLASS] Why did you withdraw from your online class? (Prompt for all reasons)

Q4: [IF RESPONDENT DID NOT PASS THE CLASS] What was it about the class that didn't work for you? (Prompt for all reasons) 


\section{Appendix B}

\section{Quantitative Data Dictionary}

Data element descriptors are sourced from the data dictionary of the California State Community College system office database, supporting the Accountability Reporting for California Community Colleges (ARCCC) initiative.

This element indicates whether the student is female or male.

$\begin{array}{ll}\text { CODING } & \text { MEANING } \\ \mathrm{F} & =\text { Female } \\ \mathrm{M} & =\text { Male } \\ \mathrm{X} & =\text { Unknown / non-respondent }\end{array}$


DED \# DATA ELEMENT NAME

FORMAT

SB14 STUDENT-EDUCATIONAL-GOAL

This element identifies the student's principal educational goal as reported by the student. This goal is not updated unless the student's enrollment lapses for at least an academic year.

\section{CODING MEANING}

A $\quad=$ Obtain an associate degree and transfer to a 4-year institution.

B $=$ Transfer to a 4-year institution without an associate degree.

C = Obtain a two year associate's degree without transfer.

D = Obtain a two year vocational degree without transfer.

$\mathrm{E} \quad=$ Earn a vocational certificate without transfer.

F $\quad=$ Discover/formulate career interests, plans, goals.

$\mathrm{G} \quad=$ Prepare for a new career (acquire job skills).

$\mathrm{H} \quad=$ Advance in current job/career (update job skills).

I = Maintain certificate or license (e.g. Nursing, Real Estate)

$\mathrm{J} \quad=$ Educational development (intellectual, cultural).

$\mathrm{K}=$ Improve basic skills in English, reading or math.

L $\quad$ = Complete credits for high school diploma or GED.

$\mathrm{M} \quad$ = Undecided on goal.

$\mathrm{N} \quad=$ To move from noncredit coursework to credit coursework.

$\mathrm{O}=4$ year college student taking courses to meet 4 year requirements.

$\mathrm{X} \quad=$ Uncollected/unreported.

NOTE: This goal is the initial, perhaps uninformed goal of the student. After a student has reviewed assessment results, received orientation or other services which expand a student's understanding of the requirements necessary to achieve the goal, goal is collected again and reported in (SM01) Matriculation Goal Element. 
This data element is used to report ALL the ethnicities with which a student identifies. Each position requires a value of ' $\mathrm{Y}$ ' for Yes or ' $N$ ' for No to be reported. Position 1, Hispanic, Latino, has three values ' $Y$ ', ' $N$ ' or ' $X$ '. If the student does not select ' $Y$ ' or ' $N$ ' then ' $\mathrm{X}$ ' is reported.

\section{Position}

1 - Hispanic, Latino

2 - Mexican, Mexican-American, Chicano

3 - Central American

4 - South American

5 - Hispanic Other

6 - Asian Indian

7 - Asian Chinese

8 - Asian Japanese

9 - Asian Korean

10 - Asian Laotian

11 - Asian Cambodian

12 - Asian Vietnamese

13 - Filipino

14 - Asian Other

15 - Black or African American

16 - American Indian / Alaskan Native

17 - Pacific Islander Guamanian

18 - Pacific Islander Hawaiian

19 - Pacific Islander Samoan

20 - Pacific Islander Other

21 - White

\section{Coding}

Y or $\mathrm{N}$ or $\mathrm{X}$

$\mathrm{Y}$ or $\mathrm{N}$

$\mathrm{Y}$ or $\mathrm{N}$

$\mathrm{Y}$ or $\mathrm{N}$

Y or N

Y or $\mathrm{N}$

Y or $\mathrm{N}$

Y or $\mathrm{N}$

$\mathrm{Y}$ or $\mathrm{N}$

$\mathrm{Y}$ or $\mathrm{N}$

Y or $\mathrm{N}$

Y or $\mathrm{N}$

Y or $\mathrm{N}$

Y or $\mathrm{N}$

$\mathrm{Y}$ or $\mathrm{N}$

Y or $\mathrm{N}$

Y or $\mathrm{N}$

Y or $\mathrm{N}$

$\mathrm{Y}$ or $\mathrm{N}$

Y or $\mathrm{N}$

Y or $\mathrm{N}$ 
This element indicates whether or not the course is transferable to the University of California (UC) and/or to the California State University (CSU) on the basis of articulation agreements.

$$
\begin{array}{ll}
\text { CODING } & \text { MEANING } \\
\text { A } & =\text { Transferable to both UC and CSU. } \\
\text { B } & =\text { Transferable to CSU only. } \\
\text { C } & =\text { Not transferable }
\end{array}
$$

NOTE: If a course is coded as Transferable (A or B) then CB04 must be coded as a (D).

DED\# DATA ELEMENT NAME

CB08 COURSE-BASIC-SKILLS-STATUS

This element indicates whether the course is a basic skills course.

$$
\begin{array}{ll}
\text { CODING } & \text { MEANING } \\
\mathrm{B} & =\text { Course is a basic skills course. } \\
\mathrm{N} & =\text { Course is not a basic skills course. }
\end{array}
$$

NOTE: Basic skills courses are those courses which have been designated as such by the district, pursuant to the provisions of Title 5: Section 55035 Total units earned in credit remedial coursework is limited by Title 5 , Section 55035 . 
This code is used to indicate the degree to which a course is occupational, and to assist in identifying course sequence in occupational programs.

\section{CODING $=$ MEANING}

A = Apprenticeship (offered to apprentices only): The course is designed for an indentured apprentice and must have the approval of the State of California, Department of Industrial Relations, Division of Apprenticeship Standards. Some examples of apprenticeship courses are: Carpentry, Plumbing and Machine Tool.

$\mathrm{B}=$ Advanced Occupational (not limited to apprentices): Courses are those taken by students in the advanced stages of their occupational programs. A " $\mathrm{B}$ " course is offered in one specific occupational area only and clearly labels its taker as a major in this area. Priority letter " $\mathrm{B}$ " should be assigned sparingly; in most cases no more than two courses in any one program should be labeled "B". Each "B" level course must have a "C" level prerequisite in the same program area. Some examples of "B" level courses are: Dental Pathology, Advanced Video Tape, Advanced Applied Acting, Legal Secretarial Procedures, Contact Lens Laboratory, Advanced Radiology Technology, Fire Hydraulics, Livestock and Dairy Selections, Real Estate Finance, Cost Accounting.

C = Clearly Occupational (but not advanced): Courses will generally be taken by students in the middle stages of their programs and should be of difficulty level sufficient to detract "drop-ins". A "C" level course may be offered in several occupational programs within a broad area such as business or agriculture. The "C" priority, however, should also be used for courses within a specific program area when the criteria for " $B$ " classification are not met. A " $C$ " level course should provide the student with entry-level job skills. Some examples of "C" level courses are: Soils, Credit and Collections, Principles of Advertising, Air Transportation, Clinical Techniques, Principles of Patient Care, Food and Nutrition, Sanitation/Safety, Shorthand, Small Business Management, Advanced Typing, Technical Engineering.

$\mathrm{D}$ = Possibly Occupational: "D" courses are those taken by students in the beginning stages of their occupational programs. The "D" priority can also be used for service (or survey) courses for other occupational Programs. Some examples of "D" level courses are: Technical Mathematics, Graphic Communications, Elementary Mechanical Principles, Fundamentals of Electronics, Typing (Beginning or Intermediate), Accounting (Beginning).

$\mathrm{E}=$ Non-Occupational: Courses are non-occupational 